\title{
THE ROLE OF BIAXIAL STRESSES IN DISCRIMINATING BETWEEN MEANINGFUL AND ILLUSORY COMPOSITE FAILURE THEORIES
}

\author{
by \\ Dr. L. J. Hart-Smith \\ ODouglas Aircraft Company, \\ McDonnell Douglas Corporation, 1991 \\ Long Beach California
}

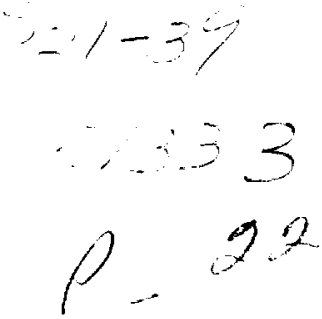

The irrelevance of most composite failure criteria to conventional fiber-polymer composites is claimed to have remained undetected primarily because the experiments that can either validate or disprove them are difficult to perform. Uniaxial tests are considered inherently incapable of validating or refuting any composite failure theory because so much of the total load is carried by the fibers aligned in the direction of the load. The Ten-Percent Rule, a simple rule-of-mixtures analysis method, is said to work well only because of this phenomenon. It is stated that failure criteria can be verified for fibrous composites only by biaxial tests, with orthogonal in-plane stresses of the same as well as different signs, because these particular states of combined stress reveal substantial differences between the predictions of laminate strength made by various theories. Three scientifically plausible failure models for fibrous composites are compared, and it is shown that only the in-plane shear test (orthogonal tension and compression) is capable of distinguishing between them. This is because most theories are "calibrated" against the measured uniaxial tension and compression tests and any cross-plied laminate tests dominated by those same states of stress must inevitably "confirm" the theory.

\section{BACKGROUND}

For several years, the author has tried to expose and rectify serious fundamental deficiencies in the most widely taught "failure theories" for composite laminates. This has proved to be a most difficult task, mainly because of a widespread reluctance to use any method not already coded on a computer or to challenge any output from the computer. The difficulty of generating valid test data with which to accept or reject any theory is also a factor.

The issue of computer codes for the new theory is being addressed in another paper. The emphasis here is on the need to validate theories by tests on structural laminates, particularly under biaxial in-plane loads. Unfortunately, there is only a limited appreciation of difficulties with the design and execution of even the standard uniaxial tests on cross-plied laminates. These problems are exacerbated by a failure to recognize that gross oversimplifications have been made in the model used to formulate most composite failure criteria. Consequently, most biaxial test coupons fail prematurely outside the test section in areas of uniaxial stress because the target biaxial strengths have been badly underestimated.

Some promoters of abstract mathematical failure models for composite materials have taken advantage of these experimental difficulties. They do not find it necessary to conduct experiments at the structural laminate level to validate predictions made by theory. Instead, they characterize the material by a series of tests at the lamina coupon level, relying on a theory with sufficient adjustable and sometimes unmeasurable parameters to match the lamina test results. Since no mathematical approximations are made in the derivations, it is implied that there is no need for further tests which, if conducted for a sufficiently wide range of stress states, might expose inconsistencies in the predictions when the model used for the theory does not represent physical reality. Conversely, redundant testing would inevitably validate a scientifically sound theory unless the experiments

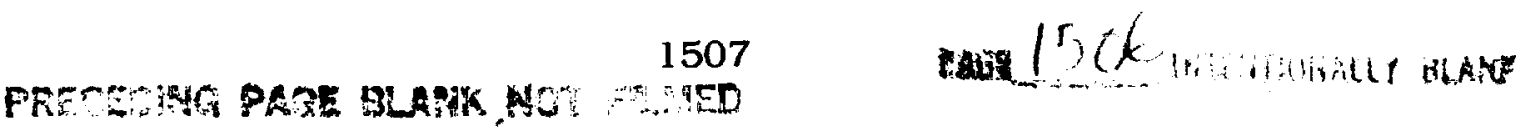


were faulty. If 10 successful tests were run to deduce eight unknown properties, the same properties should be predicted no matter which eight tests were selected for the analysis. The scheme of ensuring that redundant tests will not be conducted so that one's theory can never be challenged has also been used in bolted composite joint studies. The technique has been applied so artfully that few would question it.

Such thinking has not only led most composite structural analysts to refrain from questioning the foundations of their computer codes for strength prediction, but has also deluded some who would apply theories of ani iotropic elasticity for homogeneous materials to distinctly heterogeneous fiber-polymer composites into believ ng that there is nothing wrong with such a "simplifying" assumption, merely because the individual fibers in the composite are microscopic.

Others have justified the need for such simplifications by the complexity of micromechanics, suggesting that some simpler theory had to be developed for all those who would not use any theory far more complicated th an what they used for metallic structures. This problem is not helped by the widespread use of finite-element prosedures without ensuring that both the model and the boundary conditions simulate reality. But, to be fair, the most potent argument against micromechanical analyses is the large number of material properties that cannot be easily determined experimentally but are needed to implement the more realistic failure models.

The end result of all this is that few if any composite failure theories have ever been properly verified by experiment.

This by no means implies that all composite structures designed and built so far are unsafe; typically, liss than 1 percent of composite structures on large aircraft is actually governed by unnotched laminate strengths. The rest is dominated by joints, damage tolerance, and stiffness requirements. Empirical interpretations of d.ta are needed for joint strength and damage tolerance, while the laminate stiffnesses are not in doubt because lamination theory works for even heterogeneous materials. At least the predicted elastic constants are right, even if the strengths are wrong.

Further, nearly all composite structures built so far have been certified by test rather than by analysis. And things are likely to stay this way unless better, more realistic theories are developed.

\section{HOW MANY MEASUREMENTS ARE NEEDED TO CHARACTERIZE THE STRENGTH OF A FIBROUS COMPOSITE LAMINATE?}

Considerable confusion exists as to the number of measurements needed to characterize the strength of composite materials. The seemingly reasonable position that it is necessary to characterize longitudinal and tra nsverse strengths, in both the tensile and compressive directions, and to have some measure of the shear stren ${ }_{i j}$ th would suggest that five measurements are needed. Many composite failure models have been based on such an assumption, adopted because of the apparent ease with which those particular measurements could be made. But if one were to consider the real physics of the situation instead, one would conclude that only one measurement is needed to characterize each mode of failure. If the same mode of failure, such as yielding in ductile motal alloys, occurred under different states of combined stress, measurements made under different states of str ess would be equivalent and not independent. The value of redundant tests would be to demonstrate a consistency confirming that the theory was sound.

Thus, the five strength measurements would be appropriate only if there were precisely five modes of failure to be characterized. And, under no circumstances could these five measurements be integrated into a single smooth, continuous failure envelope. They should represent five superimposed envelopes, truncating each other locally so that one or another would govern as the state of stress varied. 
It is clear, then, that the unstated simplifying assumptions of traditional composite failure theories are so contradictory to basic laws of physics that the theories should be discarded. However, it is commonly held that any new and better theory must inevitably be more complicated than older theories and need additional data for its implementation. A claim that an entire failure envelope can be constructed from a single test result and simultaneously be more accurate than older theories based on measurements of four distinct measurements of strength seems difficult to accept, even when it is explained that additional failure modes can be covered, if needed, at the rate of one test per failure mechanism. The conclusion seems to run contrary to tradition: the new theory needs, at most, measurements of the longitudinal strength of the lamina in tension and compression, whereas older theories needed transverse strengths as well, and the omission of the transverse measurements improves the accuracy of the theory. ${ }^{*}$

Separate failure envelopes for shear failures of the fibers and in-plane shear failures for the matrix can be superimposed at the lamina level, as shown in Figure 1. Their origins are offset to account for residual thermal stresses induced by curing at elevated temperatures. Apart from traditional elastic constants such as Young's moduli and the various Poisson's ratios, Figure 1 would be based on only two measurements of strength, one for the fibers and one for the matrix.

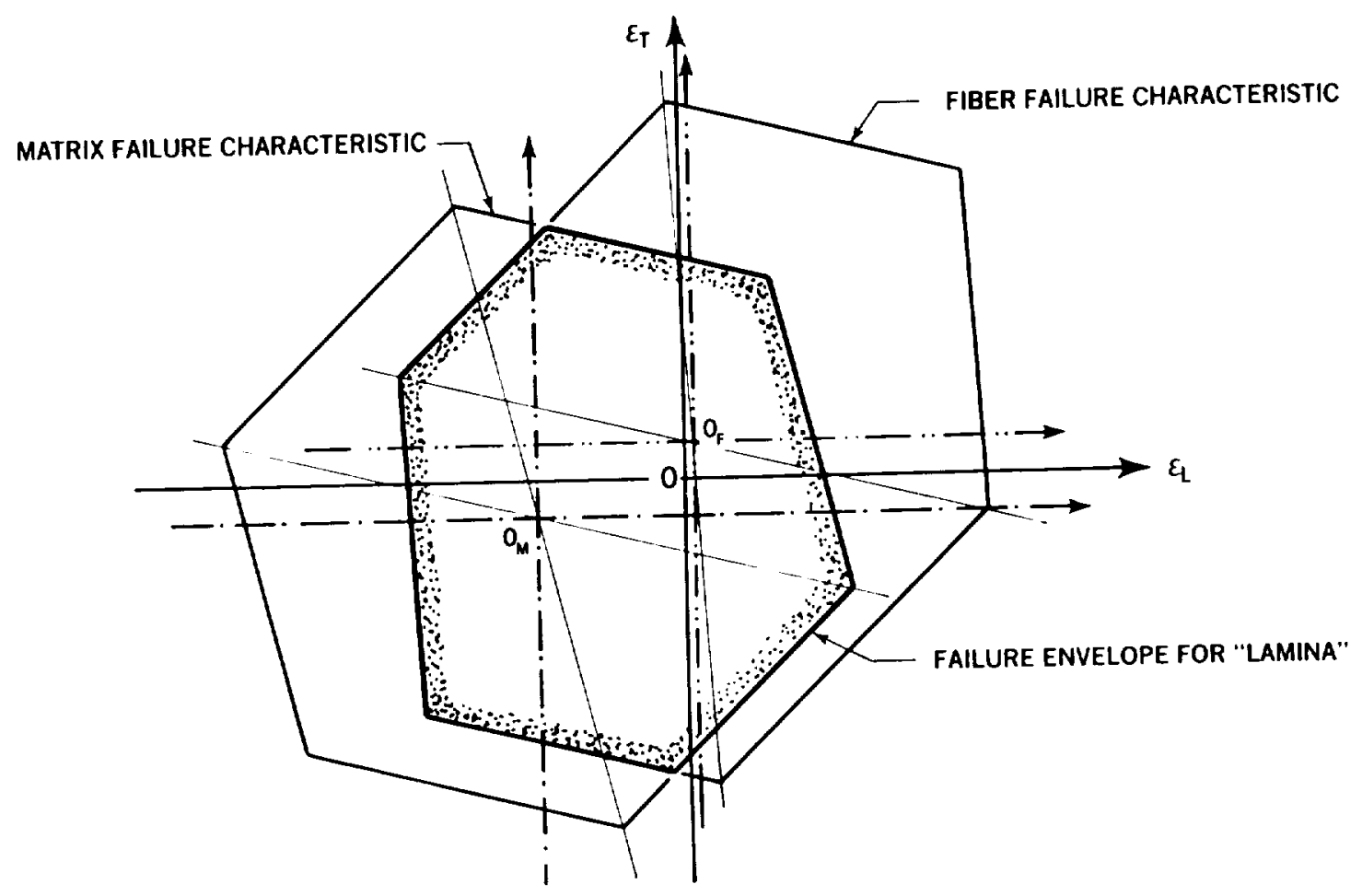

FIGURE 1. SEPARATE FAILURE CHARACTERISTICS FOR FIBERS AND MATRIX

\section{THE INVALIDITY OF ASSOCIATING COMPOSITE FAILURE CRITERIA WITH HILL'S WORK ON PLASTICITY IN METALS}

Many composite failure theories have been falsely likened to the unrelated work of Hill (Reference 2) on the plastic yielding of slightly anisotropic ductile metals. The very name Tsai-Hill for one of the early composite

- The transverse-tension strength measured on a unidirectional lamina has no relevance to any in-plane strength of a multidirectional structural laminate, whether the failure be matrix-dominated or fiber-dominated. However, an empirically deduced "effective" transverse-tension strength can be used to provide a separate failure characteristic truncating the fiber-failure envelope locally throughout part of the tension-tension stress quadrant (see Reference 1.) 
failure theories (Reference 3) implies such an association. In fact, there is absolutely no similarity between th: two situations. Hill's theory of plasticity characterizes the yielding of a homogeneous material under various states of combined stress by a single mechanism, while the other theory and its innumerable clones refer to failures by at least four and sometimes five different mechanisms of a distinctly heterogeneous composite.

If Hill had tried to adapt his own methods to predicting the strength of fibrous composite laminates, he would most likely have developed a separate curve for each possible failure mechanism. One or another mechanisnı would prevail, depending on the state of combined stresses, and the failure "envelope" would have been kinked wherever the failure mechanism changed. Instead, today, industry and academia alike have what can only b: described as a plethora of meaningless smooth curves passed through unrelated data points as the "characterization" of unidirectional composites. These curves then serve as the basis for predicting the strength of cross-plied composite laminates.

This misunderstanding is highlighted in Figure 2, in a different context, to illustrate the absurdity of the conventional composite failure model shown in Figure 3. Figure 4 shows a further variation of this theme. In ever case, some meaning can be ascribed to the axes themselves, no matter how difficult they may be to measure: the problem is in interpreting intermediate points, as indicated by the question mark in each of the figures.

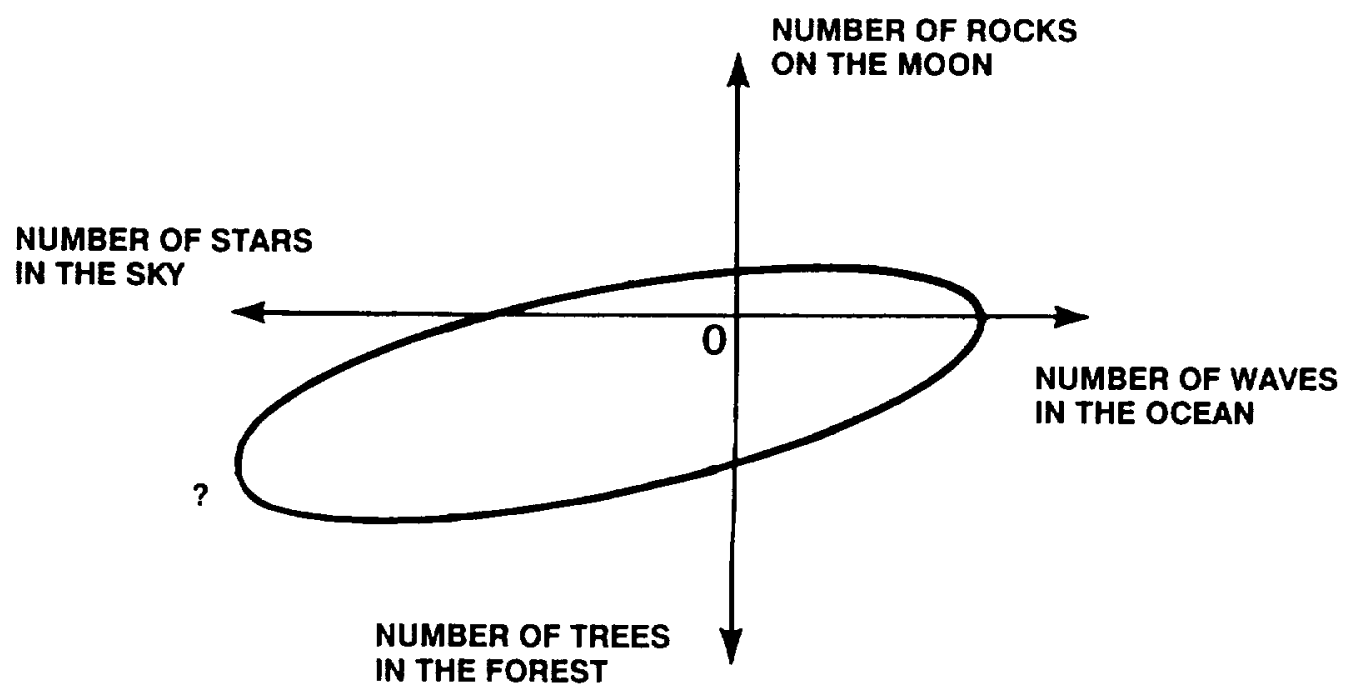

FIGURE 2. ONE EXAMPLE OF A MEANINGLESS CURVE DRAWN THROUGH UNRELATED DATA POINTS

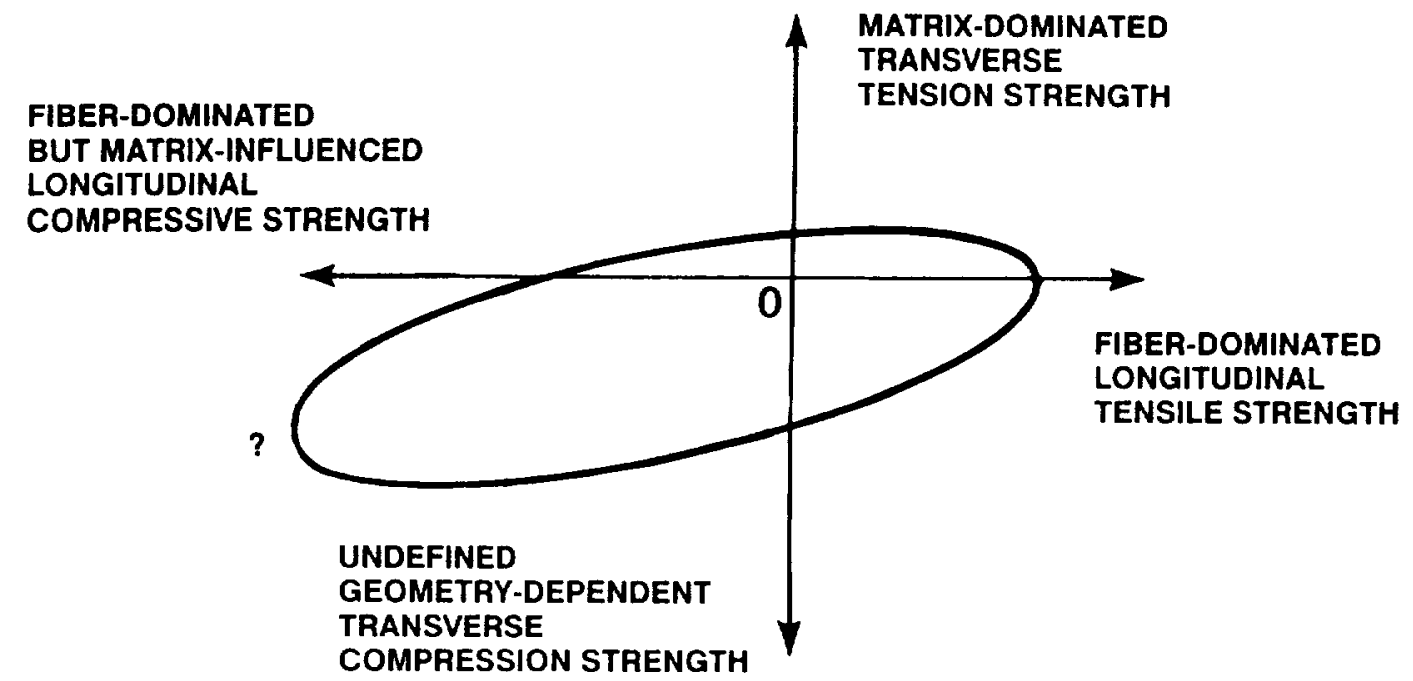

FIGURE 3. AN EQUALLY MEANINGLESS CURVE DRAWN THROUGH UNRELATED DATA POINTS 


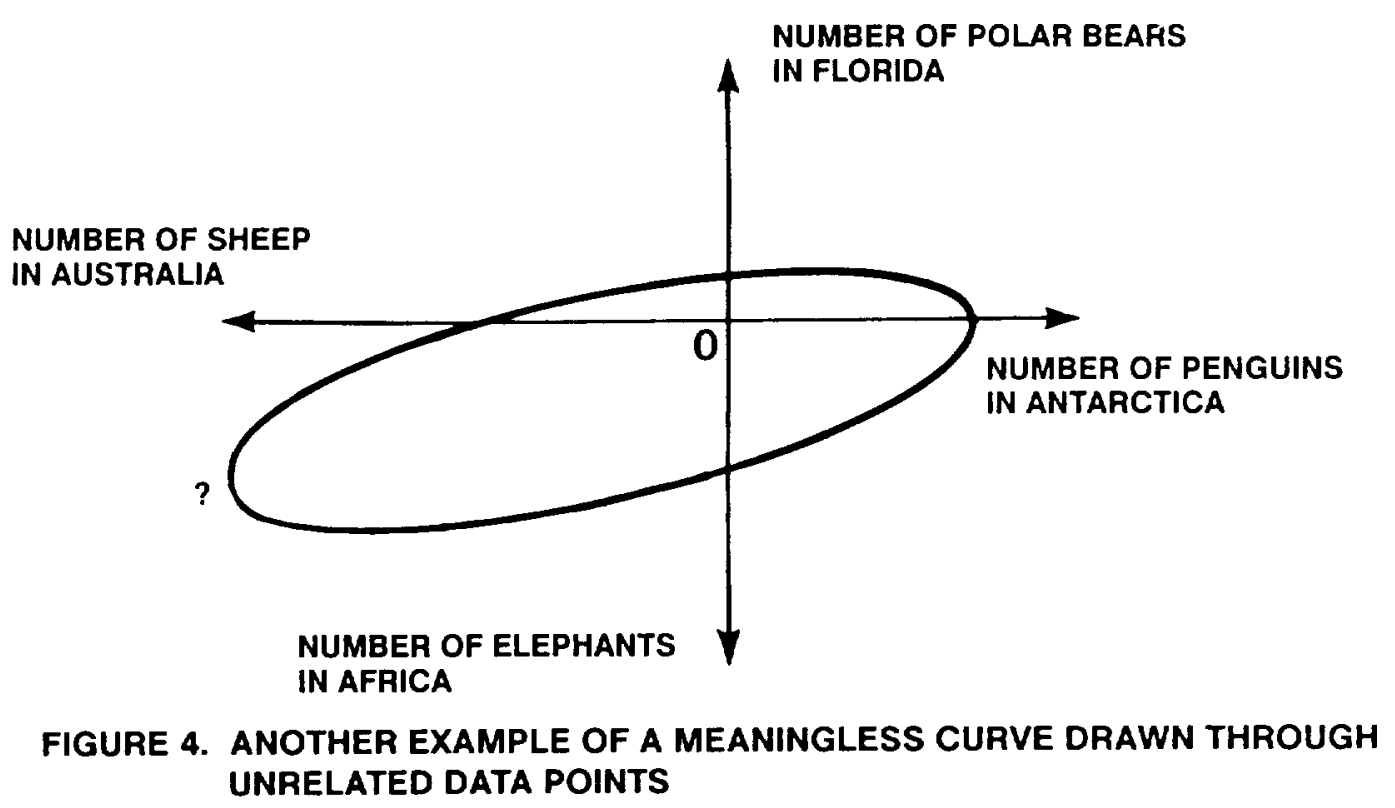

Hill's use of three parameters to characterize his failure surface for mildly anisotropic materials may seem to contradict the author's assertion that only one should be needed when only one failure mode is involved. However, while it takes only two points to specify a straight line, the line may be specified by three or more points, provided that they are merely redundant and not contradictory. The Tresca and von Mises' criteria for ductile materials require only one parameter each to characterize the yield of a ductile material under any set of combined stresses. Logic suggests that, if one were to perform the necessary algebra, one could also deduce an equivalent single parameter for orthotropic materials, provided that only one failure mechanism was involved. The other two parameters would be replaced by elastic constants characterizing the degree of anisotropy. Hill found a way of circumventing such tedious work. In all probability, he arrived at a far more elegant expression of essentially the same result, or an extremely close approximation to it.

If three distinct modes of failure had been involved for different states of stress - yielding under shear, short-transverse-grain delaminations, and brittle fracture, for example - no single characterization of the strength would be possible. But neither would Hill's three parameters suffice since they would merely represent the redundant specification of one mode of failure. These three different modes of failure would certainly be associated with three different strengths along the principal material axes, but that is the end of the similarity. Their characterization would require three physically independent parameters and the failure surface would certainly not be smooth.

Rowlands (Reference 4), in an excellent summary of the history of composite strength failure theories, reveals the extent of misinterpretation of Hill's work. He states that "Hill's theory was adapted by Azzi and Tsai as a strength criterion for composites" (p. 76), and later states "While it is not common to use Equation (43) [one particular formulation of Hill's theory] with composites, this concept does form the basis of several composite strength criteria" (p. 90). But, later on the same page he states that "Unlike the maximum stress or strain criteria, Equation (43) contains interaction among the stresses and therefore involves combined modes of failure." [emphasis added]. Rowlands also states (pp. 90 and 91) that "This led Hill (1950) to propose an orthotropic yield condition" [emphasis added]. How does this imply "combined modes of failure?"

Nothing in Hill's work addresses more than one mode of failure and he should therefore be spared the ignominy of association with the many abstract mathematical failure theories for composite materials. Yet, in the United Kingdom and Europe, Tsai's misinterpretation of Hill's theory of anisotropic plasticity is referred to as the "modified Hill theory."

Earlier, Rowlands states (p. 86) that "Yielding normally does not occur in fiber-reinforced plastics in the same sense as in metals. Nevertheless, many of the orthotropic strength theories are anisotropic extensions of iso- 
tropic yield criteria." He also states (p. 96), "In an effort to more accurately predict experimental results Ts:ii and Wu (1971) proposed a lamina failure criterion having additional stress terms not appearing in theories such as the Hill analysis."

What is involved is a simple curve-fit, which has no association with the physics of the situation. Additional tests are needed to provide data for each additional term included in the theoretical failure model. Ironically, as is well known, the Tsai-Wu failure model (Reference 5) contains one interaction term for which no reliabe measurement has been found. Instead, it is customarily assigned the value 0.5 or zero.

\section{THE NEED FOR BIAXIAL RATHER THAN UNIAXIAL LAMINATE TESTS TO VALIDATE FAILURE THEORIES}

Unfortunately, the characteristics of fiber-polymer composites in which strong, stiff fibers are embedded in relatively soft matrices are such that "failure theories" can never be validated, or even repudiated, by uniaxial testing alone. Indeed, the author's Ten-Percent Rule (Reference 6) for preliminary design by mental arithmetic works as well as it does only because of the dominance of the load carried by fibers aligned with the applie.J load. Only the biaxial strengths of cross-plied laminates provide a means of differentiating between good an.j bad methods. And it transpires that at least two theories can be validated if attention is confined to only those biaxial in-plane stresses in which the stress components have the same sign. Of all the possible states of stress with which to assess composite failure theories, the in-plane shear state is the most crucial. But a theory cannct be validated without also considering biaxial stresses of the same sign.

The criticality of the in-plane-shear state of stress in differentiating between plausible and implausible failure models is explained in Figure 5. Except for the tension-compression (shear) quadrants, virtually the same composite laminate strengths would be predicted by the author's generalized maximum-shear-stress failur:

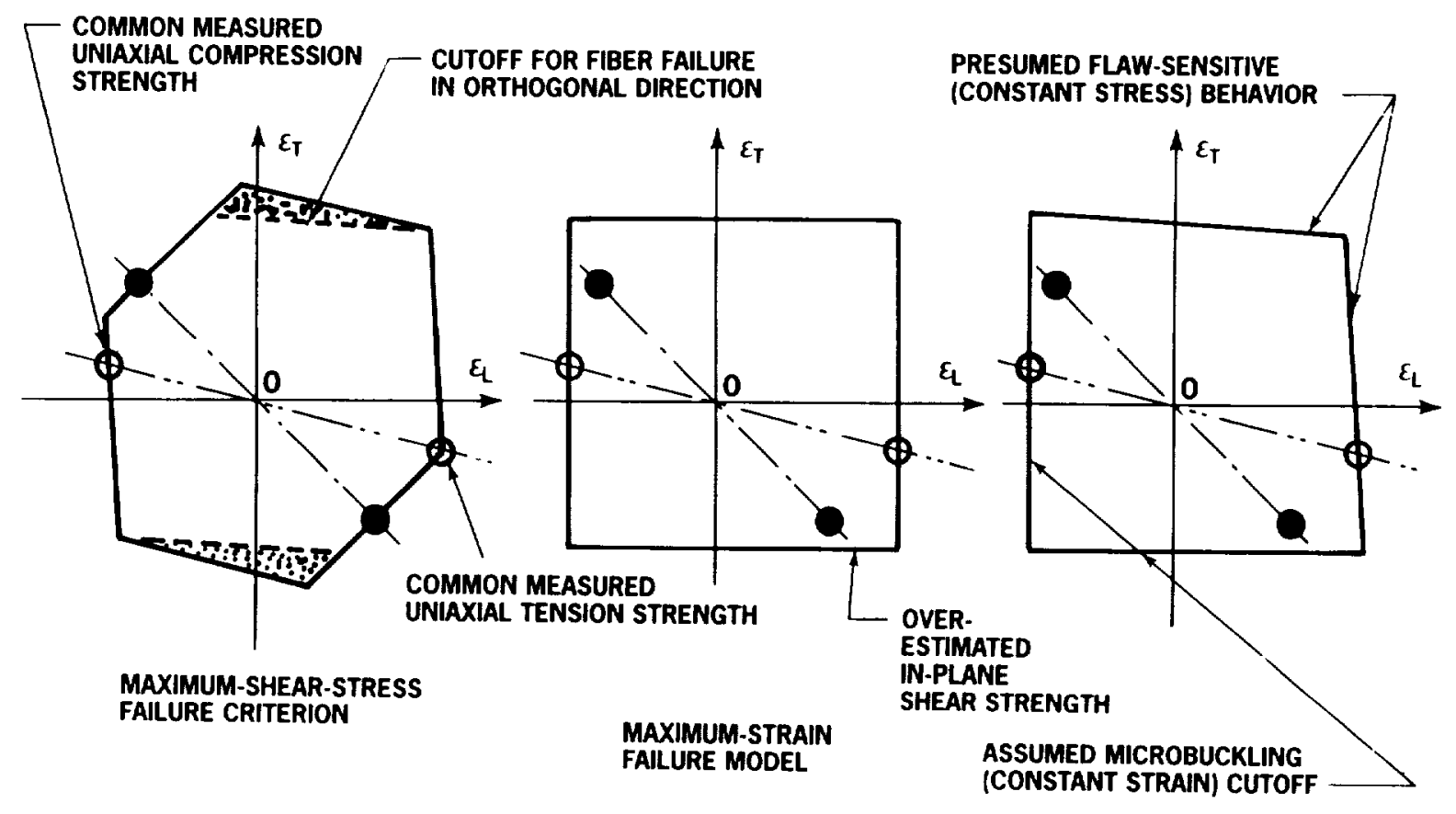

NOTE: ONLY THE IN-PLANE SHEAR TEST CAN DISTINGUISH BETWEEN THESE PHYSICALLY DIFFERENT FAILURE MODELS SINCE THE UNIAXIAL TENSION AND COMPRESSION STRENGTHS (OPEN SYMBOLS) ARE COMMON THROUGHOUT

FIGURE 5. IMPORTANCE OF BIAXIAL TESTING TO DISTINGUISH BETWEEN FAILURE MECHANISMS 
criterion, the maximum-strain model, and a combination of flaw-sensitive fracture in tension and some form of instability in compression. The other predicted strengths are similar because all three models are empirically forced to pass through the same measured tensile and compressive strengths under uniaxial loads. The theories predict different strengths only under in-plane shear loads, so that is the only test capable of validating or repudiating any of these proposed failure mechanisms.

On the other hand, agreement between test and the predictions in all the stress quadrants using the author's failure model does not actually prove that flaw-sensitive fracture could not occur under tensile loads alone. All that can be said with certainty is that the other models cannot possibly be valid throughout all states of combined stresses.

\section{USE OF MATRIX “FAILURES” TO TRUNCATE PREDICTED FIBER-DOMINATED STRENGTHS}

A number of theories postulate that the maximum-strain theory is valid for the fibers but that it sometimes needs truncating to allow for matrix-dominated failures. This concept appears to result from a perception that the fiber-based maximum-strain theory is in such close agreement with tests for some states of stress that it must be a valid basis for a composite failure criterion, even if it does need some minor adjustment for other states of stress.

Perhaps the best known of these works on failure criteria with multiple characterizations is by Puck (Reference 7), who has influenced others to follow his rationale. In one respect, he is quite correct in separating the failure criteria for the fibers and the resin, although he seems to have been unaware that he could not possibly characterize the state of stress in the resin with a simple theory that does not provide for residual curing stresses. Similarly, more complex treatments such as those of Grant and Sanders (Reference 8) have also relied on presumed matrix failures to modify the maximum-strain failure model for shear- and compression-dominated loads.

As with much of Tsai's work, use of postulated matrix failures to truncate a fiber-failure envelope seems quite plausible. And, under other circumstances, such truncations are undoubtedly true. However, in this specific case, the cutoffs are not consistent with other test data. The very highest measured in-plane shear strength of an all $\pm 45^{\circ}$ laminate has the fibers failing at barely half the axial strain at which they fail under uniaxial loads. This implies that the matrix strains are also barely half as high, which leads to the following question: How can a matrix failure be used to explain a fiber-dominated in-plane shear strength when both the matrix and the fiber can withstand twice as much load under uniaxial tension or compression?

Researchers such as Puck, and Grant and Sanders must have been aware that the fiber-dominated maximum-strain failure model predicted excessive strengths for in-plane shear-dominated loads since their "matrix" failure equations truncated those regions - and sometimes the compression-dominated regions - without changing predictions for the tension-tension quadrant. It seems strange that these authors and others did not accept the same fiber-dominated maximum-strain failure model as a basis for a complete failure criterion and modify the fiber failure criterion for those states of stress for which the model was inadequate. This would have produced an even better theory and avoided the need to introduce many other experimentally determined reference strengths for the theory.

The truncated maximum-strain theory proposed in Reference 9 is almost indistinguishable from the author's generalized maximum-shear-stress failure criterion for orthotropic materials such as carbon fibers, and differs from the original untruncated maximum-strain model only for in-plane shear-dominated loads. This approach limits predicted in-plane shear strengths just as effectively as matrix cutoffs, but without doubling the number of input properties needed for the analysis. In any case, it is more in keeping with the physics of the problem. 
Curiously, work by Grimes and others at Northrop (Reference 10) included a cutoff with similar consequences but for entirely different reasons. Grimes imposed a limit on the shear deformation a resin matrix could withstand if there were no fibers in some direction to restrict the strain. He set the limit in the form of a shear strain between the $0^{\circ}$ and $90^{\circ}$ directions for either a woven or unidirectional layer of composite material. He intendid to confine the matrix to elastic deformations only: the shear strain limit was set slightly higher than that associated with the unidirectional tension state of stress, so as not to undercut that seemingly valid test result. But, although he was not aware of this at the time, the in-plane shear cutoff also implied a limit on the axial strai is of any fibers in the $\pm 45^{\circ}$ directions to far below the fiber strains which the maximum-strain failure model would have permitted. Indeed, Grimes's cutoff has virtually the same effect on predicted fiber-dominated strengths in the tension-compression quadrant as the author's own theory. And to think that it all originated from a desire to prevent the matrix from cracking! Nevertheless, the linear limit on design shear strains in the matrix implies that the actual ultimate failure would occur at higher loads. There is no evidence to support this.

In the late 1960s, long before Grimes's work was published, entirely empirical truncations for in-plane she:ir strengths were made at Grumman Aircraft on the lamina rather than on the fiber or matrix, to achieve a similiar end (see Reference 11).

These works, as well as that by Black (Reference 12), shown in Figure 6, are noteworthy because they imply (1) an acknowledgment that classical composite failure theory is inferior to empirical modifications of the popular maximum-strain failure model for fiber-polymer composites, and (2) an acceptance of predicted strengthis similar to those later predicted by the author using a generalization of the maximum-shear-stress failure criterion as his physical model.

Despite a paucity of publications on this topic and a lack of agreement on a single failure model, the aerospace industry has found reliable empirical techniques to predict the strength of composite laminates quite independently of the neoclassical mathematical theories of anisotropic elasticity for truly homogeneous materials.

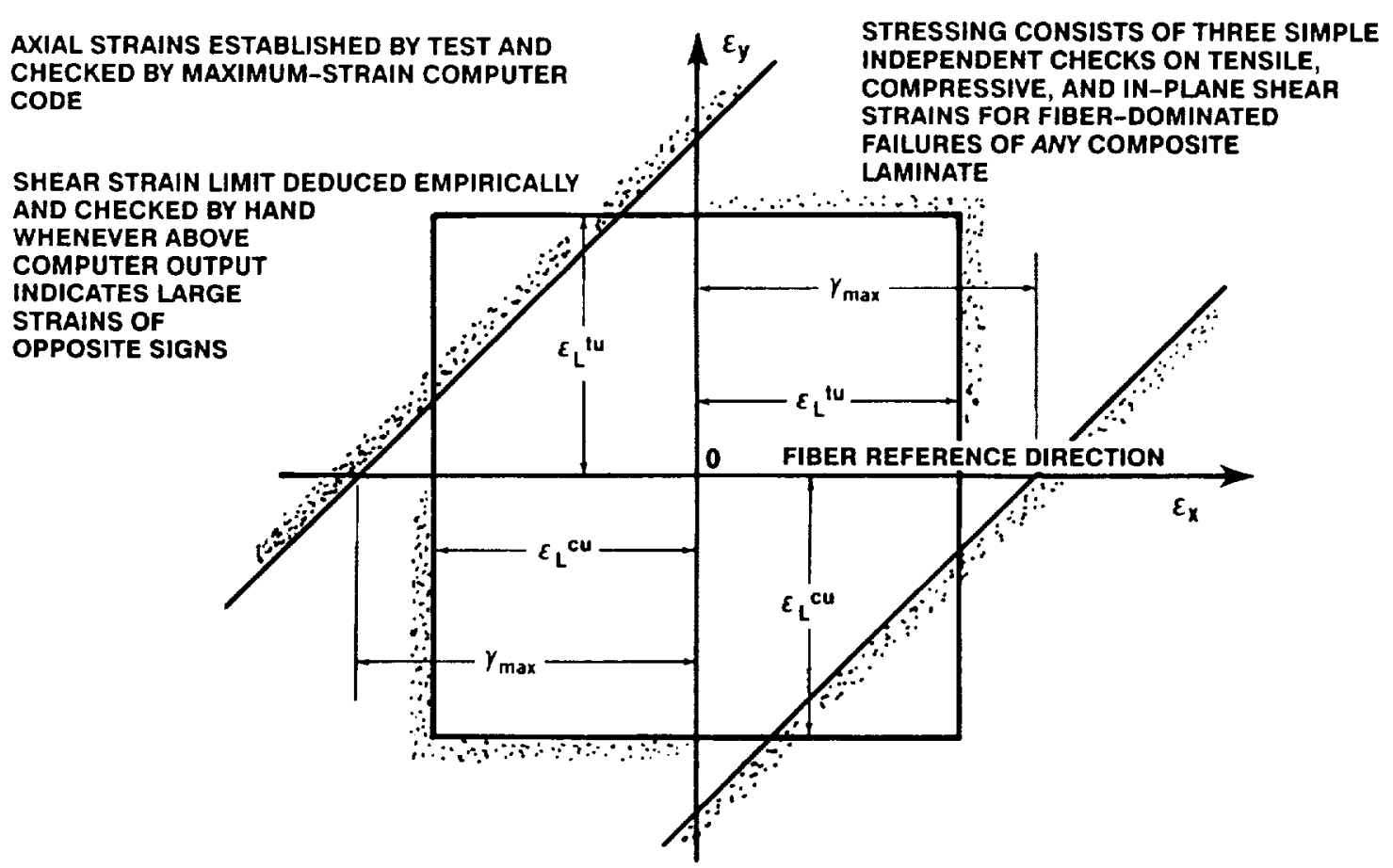

FIGURE 6. BLACK'S FIBROUS COMPOSITE FAILURE CRITERION, AS USED ON THE C-17 


\section{THE TEN-PERCENT RULE}

The many abstract mathematical theories surveyed by Rowlands (Reference 4) that purport to be capable of predicting the strength of structural composite laminates would seem to suggest that there is something difficult and mysterious about the task. On the contrary, provided that one does not lose track of physical realism in the model, it is easy to generate plausible sets of uniaxial and biaxial predicted strengths with the simplest of mathematical techniques, as the following approximate methods developed by the author are intended to show. Admittedly, it is necessary to restrict the theory to fiber-dominated failures a priori, but no skilled composite designer would knowingly waste expensive fibers in inferior structures in which the inexpensive matrix really does fail first. This theory is also restricted to fiber-polymer composites in which strong, stiff fibers are embedded in relatively soft matrices. But this limitation also is met by the great majority of composite materials, such as carbon-epoxy, fiberglass-epoxy, and boron-epoxy. There is also the customary restriction to fibers patterns in the $0^{\circ}, \pm 45^{\circ}$, and $90^{\circ}$ family, with equal numbers of fibers in the $+45^{\circ}$ and $-45^{\circ}$ directions. Some of the simplifications are lost for arbitrary laminate patterns, and a computer code is needed to apply the same physical model in such cases.

The basis of the simple analysis is that, for a load in the 0-degree direction, the longitudinal strength and stiffness of cross-plied laminates can be deduced by applying a simple factor to the appropriate unidirectional 0 -degree strength and modulus of a unidirectional tape laminate. The reference strength and stiffness are adjusted for the effects of the environment and must be established experimentally, as for any other composite failure theory. The strengths may need to account for the load direction (tension or compression) as well. Laminates made from biwoven fabrics can be analyzed the same way by first analytically decomposing the cloth into equivalent orthogonal tape layers. This simple theory is set apart from the others by its ease in computing the scaling factor. Each 0-degree ply counts as one unit of strength and stiffness, while every cross-ply* contributes only $1 / 10$ th as much to the strength and stiffness. On that basis, a $0^{\circ} / 90^{\circ}$ laminate would have $(1+0.1) / 2=$ 0.55 as much strength and stiffness as an all- $0^{\circ}$ laminate. Likewise, a quasi-isotropic laminate would be predicted to have $(1+3 \times 0.1) / 4=0.325$ as much strength and stiffness as an all- $0^{\circ}$ laminate. An all- $90^{\circ}$ or entirely $\pm 45^{\circ}$ laminate would be expected to have about $1 / 10$ th of the strength and stiffness of the all- $0^{\circ}$ laminate, but those particular properties are really matrix-dominated and the predictions may not always be relied on for such plies in isolation.

Biaxial strengths for stresses having the same sign are then predicted on the basis of the maximum-strain theory for fibrous composites. For uniaxial loads with a strain $\epsilon$ in the 0 -degree direction, any $90^{\circ}$ fibers would be strained by $-\nu \epsilon$, while $\pm 45^{\circ}$ fibers would develop an axial strain of $(1-v) \epsilon / 2$ times the strain in the $0^{\circ}$ fibers, as explained in Figure 4 of Reference 13. Here, the Poisson's ratio $v$ refers to $v_{x y}$ of the laminate. For a quasiisotropic laminate, $v_{x y}$ is inevitably very close to 0.33 , as derived in Reference 6 , while it is only 0.05 for the $0^{\circ} / 90^{\circ}$ laminate but almost 0.8 for an entirely $\pm 45^{\circ}$ laminate.

Consequently, a uniaxial 0-degree load on a quasi-isotropic laminate would strain the $\pm 45^{\circ}$ fibers to only one-third of their ultimate capacity. Since the stress on those fibers would contribute only half as much after rotation to the reference 0 -degree direction, an improved estimate of the scaling factor for the strength and stiffness of this laminate would be $(1.0+0.1+2 \times 0.333 \times 0.5) / 4=0.358$, a value adequate for design purposes. However, if we examine the biaxial rather than the uniaxial stress state, all the fibers must now be stressed equally and the scaling factor would then become $(1.0+0.1+2 \times 1 \times 0.5) / 4=0.525$, or some 50 percent higher than the strength under a uniaxial load.

This easily established increase in strength can never be demonstrated by the common kind of "biaxial" test specimen shown in Figure 4 of Rowlands' work (see Reference 4), the key features of which are summarized

- Here, the author is using the term cross-ply in its general form, to denote any ply other than a 0-degree ply. This is contrary to efforts to confine the designation to only 90-degrec plies and to use the confusing term "angle ply" to designate all other directions except 0 and 90 degrees. 
in Figure 7 of this paper. The biaxially loaded interior of the test coupon cannot possibly experience a higher stress than that needed to fail the uniaxially loaded fingers around the periphery. The most obvious demonstration of this deficiency is testing for the biaxial strength of a $\pm 45^{\circ}$ laminate which, by definition, must be the same as for a $0^{\circ} 190^{\circ}$ laminate. The surrounding $\pm 45^{\circ}$ fingers would have less than one-fifth of the required strength to fail the interior test section of this specimen. Even the quasi-isotropic laminate is 50 -percent stronger under equal biaxial stressing than when loaded uniaxially.

This widespread error in trying to experimentally determine the biaxial strength of composite materials using test coupons which are inherently incapable of providing the correct result has been a major reason why so many scientifically unsound composite "failure theories" have not been exposed.

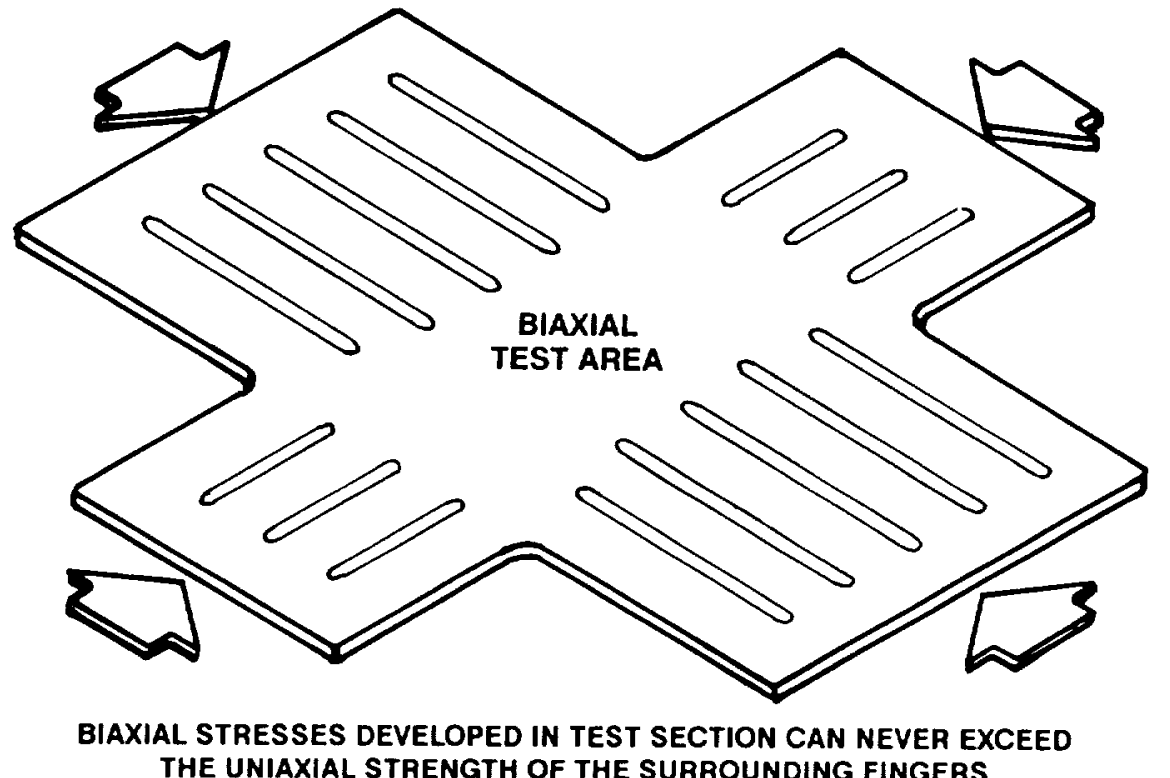

FIGURE 7. DEFECTIVE BIAXIAL TEST SPECIMEN

In Reference 14, the author proves that biaxial testing would indeed be a very difficult task, requiring a large circular sandwich plate supported around its periphery and loaded by lateral pressure, as shown in Figuri: 8 , if premature failure at some uniaxially stressed area is not to precede failure in the biaxially loaded central test section. Such an expensive specimen has yet to be tested, although the author is confident that it will eventually be used by those who design and build submarines since knowing the true biaxial compressive strength of $\mathrm{cc} \cdot \mathrm{m}$ posite laminates is so critical to the success of their activities.

However, in Reference 15, Swanson and Nelson used pressurized tubes with varying tensile axial loads to prove beyond any reasonable doubt that the maximum-strain theory is acceptable - and unlikely to be improved upon - for carbon-epoxy composites in the tension-tension quadrant (see Figure 9). Interestingly, their finding that the Tsai-Wu "last-ply" failure model was totally inconsistent with Swanson's test data as long ago as 1986 seems to have had even less effect on the technical community than this author's efforts.

Some test data in the compression-compression quadrant seem to support the author's predictions about the straight-sided form of the failure envelope. However, the strengths measured a re all too low, as are Swanson's in this stress domain. New tests are needed to truly characterize composite materials under biaxial compressive stresses.

Nevertheless, the author contends that there is really no need to directly measure the biaxial strengths of fibrous composites since they can be determined with an extremely high confidence level from uniaxial testing of $0^{\circ} / 90^{\circ}$ flat laminates. Because the Poisson's ratio is almost zero in this case, the biaxial strength cannot differ 


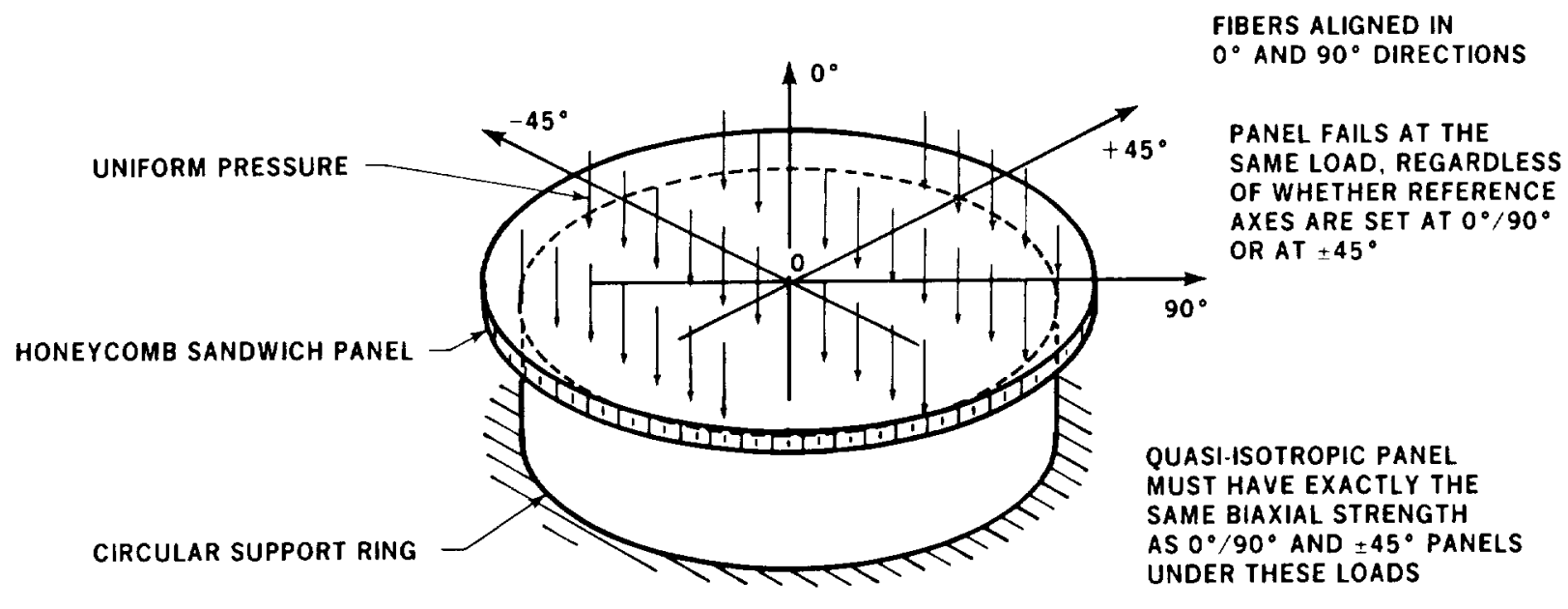

CONSEQUENTLY, ANY PANEL THAT IS A COMBINATION OF $0^{\circ} / 90^{\circ}$ AND $\pm 45^{\circ}$ LAYERS HAS THE SAME BIAXIAL STRENGTH. THAT STRENGTH IS A LITTLE GREATER THAN THE UNIAXIAL STRENGTH OF A $0^{\circ} / 90^{\circ}$ LAMINATE

FIGURE 8. BIAXIAL TEST SPECIMEN DEMONSTRATING IDENTICAL BIAXIAL STRENGTHS OF $0^{\circ} / 90^{\circ}$ AND $\pm 45^{\circ}$ LAMINATES

HOOP STRESS, MPa

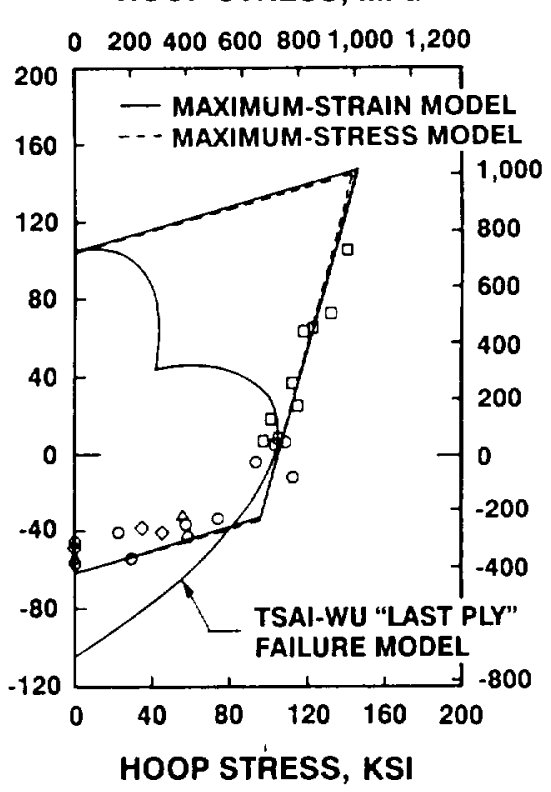

AXIAL STRESS, MPa

AXIAL STRESS, KSI

SOURCE: SWANSON, OF THE UNIVERSITY OF UTAH

\section{FIGURE 9. SWANSON'S COMPARISON OF LAMINATE FAILURE THEORIES WITH FAILURE STRESSES IN QUASI-ISOTROPIC CYLINDERS}

significantly from the uniaxial strength. According to the maximum-strain model, the biaxial strength would be higher than the uniaxial by the ratio $1 /(1-v)$, or about 1.05 . Now, the biaxial strength of an entirely $\pm 45^{\circ}$ laminate must be precisely the same because the only difference is the reference direction for the fiber axes (see Figure 8). Similarly, the biaxial strength of a quasi-isotropic laminate must also be the same, since it must be the average of these two identical quantities.

This biaxial strength serves as a kind of magic number for all laminates containing the same number of $0^{\circ}$ and $90^{\circ}$ fibers, with the remainder shared equally between the $+45^{\circ}$ and $-45^{\circ}$ directions. Once the biaxial 
strength has been obtained, the uniaxial strength is derived with great precision by multiplying the tiaxial strength by $(1-v)$, as explained below, there being only one Poisson's ratio for this family of doubly symrnetric laminates.

In the case of the $0^{\circ} / 90^{\circ}$ laminate, one would expect the normalizing factor with respect to the unidirectional lamina strength to be $0.55 /(1-0.05)=0.575$, quite close to the 0.525 deduced earlier. Likewise, the uniaxial strength of the quasi-isotropic laminate would be $(1-0.33) \times 0.575=0.383$, again only slightly above the 0.325 deduced above by treating the Ten Percent Rule in its simplest form as a rule of mixtures and the factor 0.358 deduced by resolving and summing the stresses in the various fiber directions. These various forms of simplified analysis are self-consistent, the result of being based on a physically realistic model.

Turning now to the in-plane shear strength for the same family of doubly symmetric laminates, the author has suggested a strength be selected that is equal to half the unidirectional strength of the complementary fiber pattern, with $0^{\circ} / 90^{\circ}$ and $\pm 45^{\circ}$ fiber contents interchanged (Reference 16). Thus, the fiber-dominated in-plane shear strength of an entirely $\pm 45^{\circ}$ laminate would be half the unidirectional tension or compressive strength, whichever is greater, of a $0^{\circ} / 90^{\circ}$ laminate. The scaling factor for this laminate, with respect to the uniaxial strength of a unidirectional laminate, would be $0.5 \times 0.55=0.275$. Similarly, the factor for a quasi-isotropic laminate would be $0.5 \times 0.325=0.163$, although either of the higher estimates for the second factor would be equally acceptable. The prediction of $0.5 \times 0.1=0.05$ for the in-plane shear strength of an all- $0^{\circ} / 90^{\circ}$ laminate happens to be nearly correct, but is really suspect because that particular property is obviously matrix- Iather than fiber-dominated and so contravenes the original simplifying assumptions.

Failure envelopes for these three fiber patterns, based on the Ten-Percent Rule, are shown in Figure 10. 'These envelopes are not at all similar to the predictions of Tsai's theories in Figure 11.

This simple procedure, developed by the author for predicting in-plane shear strengths, has been criticized as being unscientific and unworthy of publication. However, when a paper advocating this approach was presented in 1987 (see Reference 16), structural designers had neither reliable test specimens nor credible theoretical methods with which to establish in-plane shear strengths for laminates. What was desperately needed was something at least good enough for preliminary design. And, if this controversial idea inspired others to im rrove

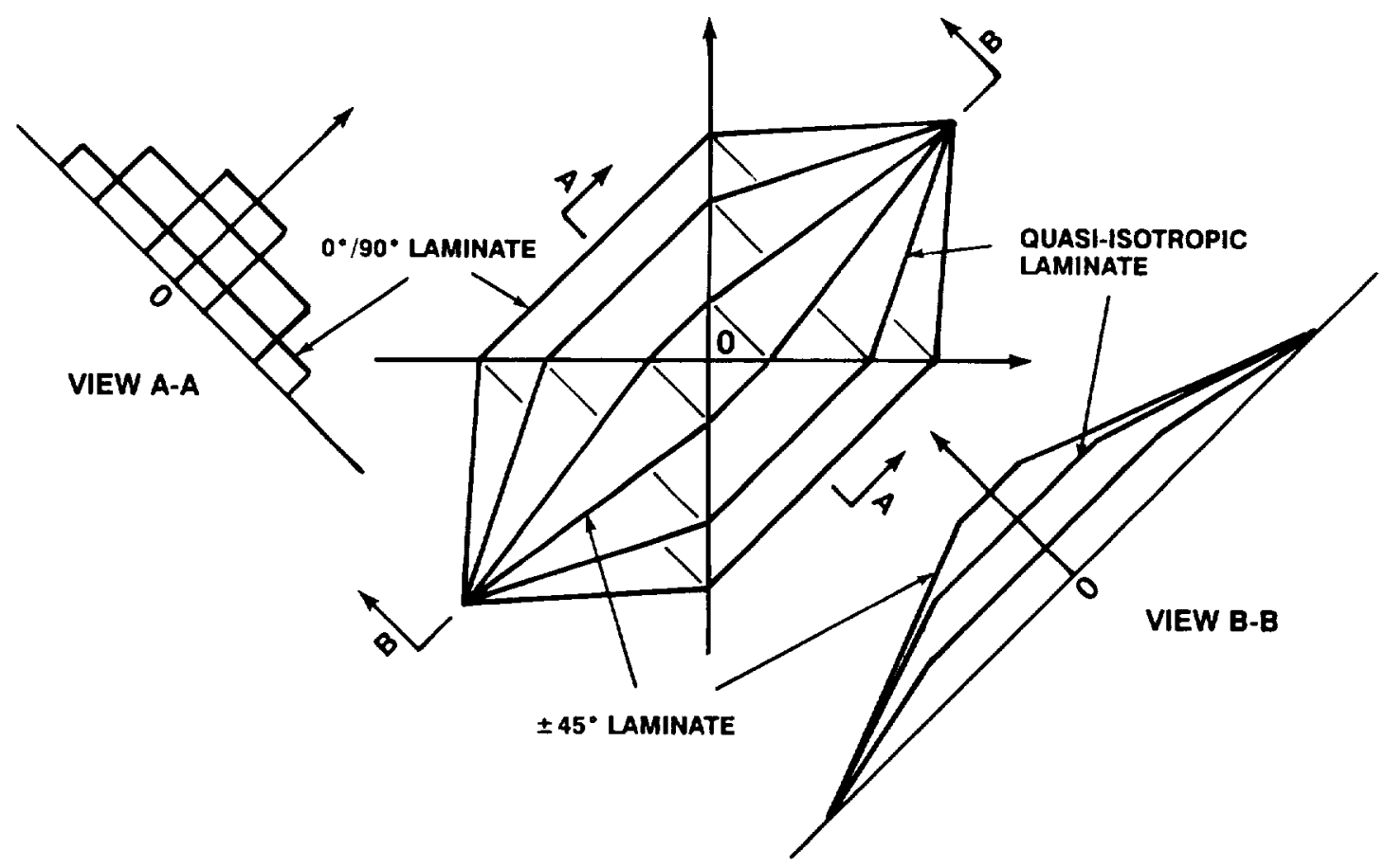

FIGURE 10. FAILURE ENVELOPES ACCORDING TO THE TEN-PERCENT RULE 


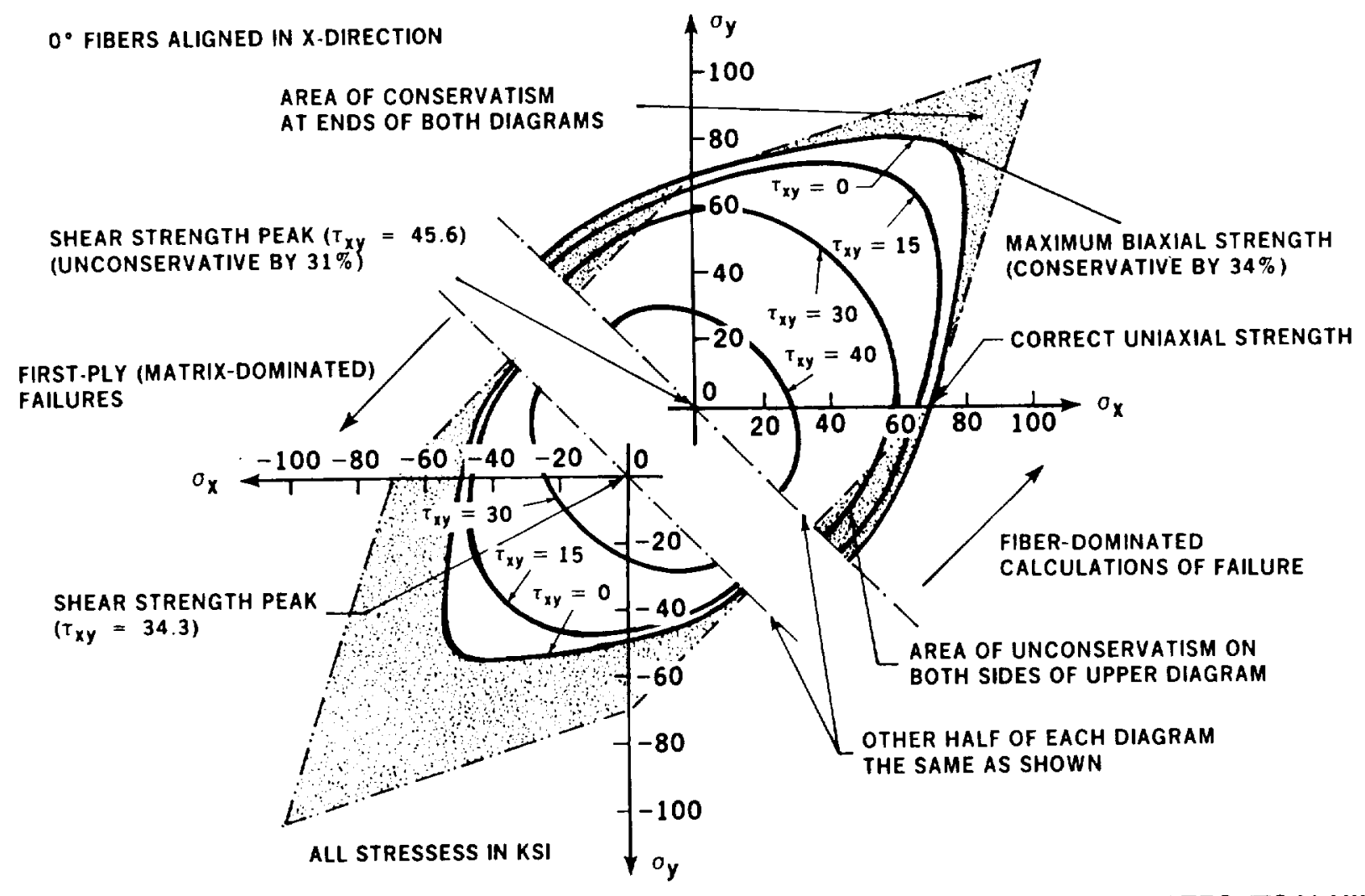

FIGURE 11. FAILURE ENVELOPE FOR QUASI-ISOTROPIC CARBON-EPOXY LAMINATES (TSAI-HILL AND TSAI-WU THEORIES)

both the test specimen designs and the analysis methods, the paper would have served an even greater purpose. Now that such predictions can be made scientifically (see Reference 17), the crude approximations of in-plane shear strength by the Ten-Percent Rule are still close enough to the best analyses to be used for formal stressing. (For a comparison between tests and theories, see Figure 15 of Reference 17).

Even the maximum-strain model of Reference 18, which is outstanding in the tension-tension and compression-compression quadrants, grossly overestimates in-plane-shear strengths, typically by 60 percent. Figure 9 of Reference 6 shows that, for the maximum-strain failure model, the in-plane shear strength is $(1-v) /(1+$ v) times as high as the biaxial strength for all doubly symmetric cross-plied laminate patterns. Therefore, in place of the factors $0.275,0.163$, and 0.05 above, the maximum-strain model would overestimate the in-plane-shear strength via the factors $[(1-0.05) /(1+0.05)] \times 0.55 /(1-0.05)=0.524,[(1-0.33) /(1+0.33)]$ x $0.55 /(1-0.05)=0.290$, and $[(1-0.8) /(1+0.8)] \times 0.55 /(1-0.05)=0.064$, respectively.

While the sample solutions here are confined to doubly symmetric fiber patterns for simplicity's sake, the original derivations of the simplified analysis methods also cover fiber patterns with different $0^{\circ}$ and $90^{\circ}$ fiber contents. However, the evaluation of the biaxial strengths for these laminates requires a pocket calculator rather than mental arithmetic.

\section{COMPARISON WITH OTHER PREDICTIONS OF BIAXIAL COMPOSITE STRENGTHS}

This section reveals gross deficiencies in corresponding predictions from a widely promoted computer code based on mathematical theories of anisotropic elasticity for homogeneous materials. Although the illustrative examples refer to only one such computer program, that of Tsai (Reference 19), the criticisms apply equally to all similar codes as well, many of which are cited in Reference 8. 
Figure 12 contains first- and last-ply failure predictions published by Tsai (Reference 19) for a quasi-isotropic carbon-epoxy laminate. Tsai advocates accepting the larger estimate for monotonically loaded test coupons on p. 12-6 of his work, as shown on the right of this figure. This recommendation is based on his proposed progressive-failure models. The author's corresponding predictions, using the same input properties but ignoring those for which there was no call, are given in Figure 13 for comparison. There are great differences, particularly with respect to the first-ply failure predictions, which do not even permit agreement under uniaxial loads The

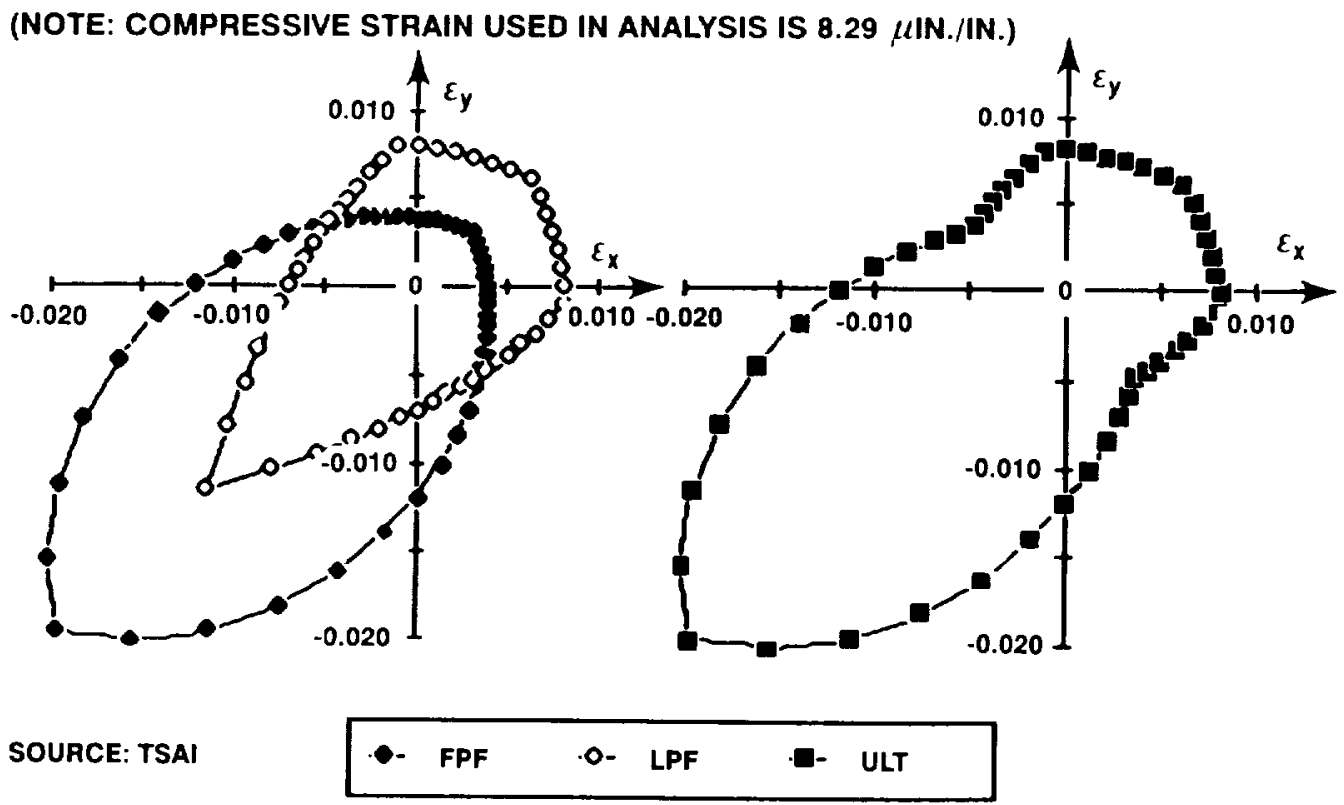

(a) FPF AND LPF ENVELOPES OF QUASI-ISOTROPIC T300/N5208 CFRP LAMINATE AND

(b) THE ULTIMATE STRENGTH ENVELOPE DEFINED BY THE OUTERMOST BOUNDARY OF THE FPF AND LPF ENVELOPES

FIGURE 12. TSAI'S FIRST- AND LAST-PLY FAILURE ANALYSES

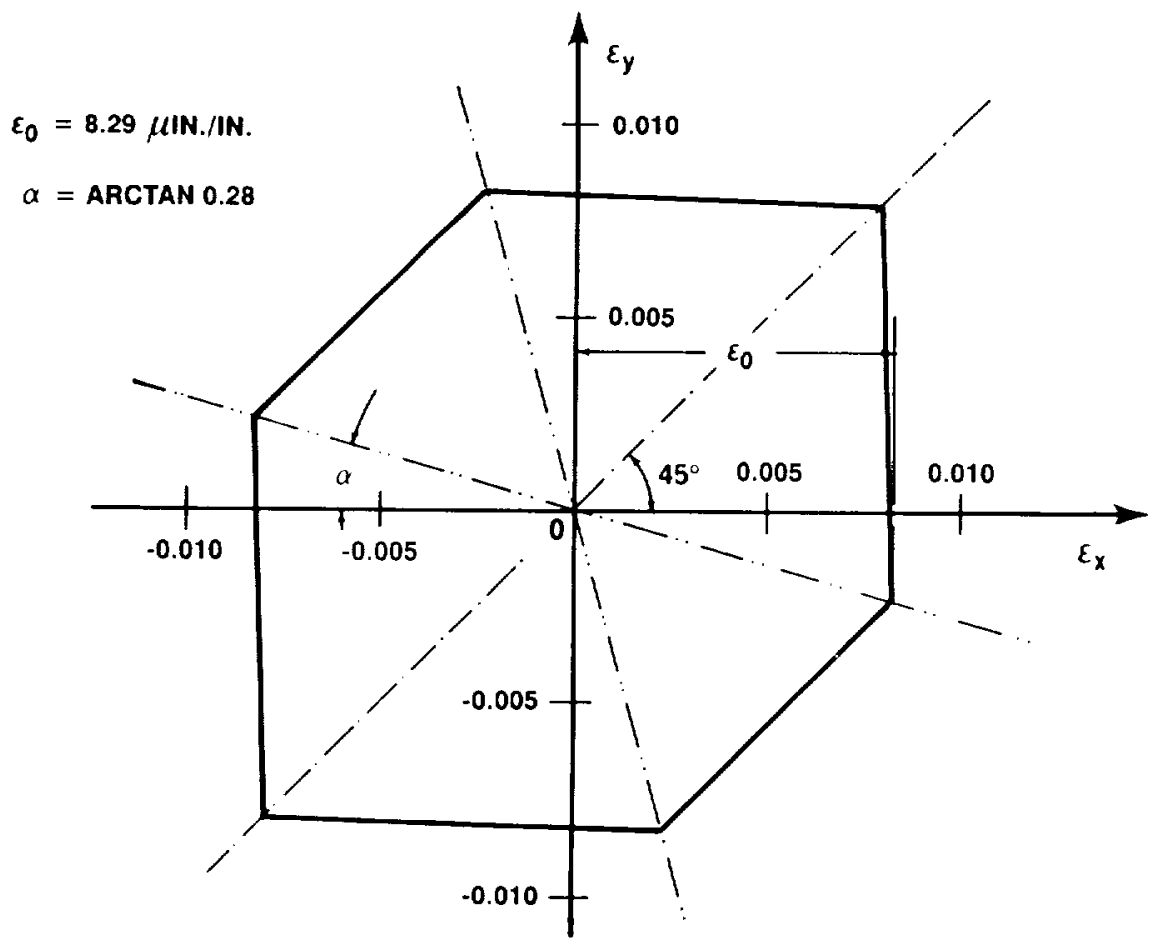

FIGURE 13. HART-SMITH'S FAILURE ENVELOPE FOR A QUASI-ISOTROPIC CARBON-EPOXY LAMINATE 
agreement with the last-ply failure predictions is better, but the failure envelope is far from smooth and continuous at the laminate level, which encourages one to question the importance of such a constraint at the unidirectional lamina level.

Tsai's first-ply predictions fall far short of the strengths predicted by the author throughout the tensiontension quadrant and greatly exceed them throughout the compression-compression quadrant. Remarkably, the strains to failure under biaxial compressive loads exceed the input unidirectional compressive strain limit by a factor of nearly 2 ! No explanation of this is provided and, in the author's opinion, none ever could be. And the justification given by Tsai for reducing these acknowledged excessive estimates requires the kind of matrix degradation that could occur only during some prior application of tensile loads in order to crack the matrix and reduce its ability to support longitudinally compressed fibers in a subsequent application of load.

Further, the predicted last-ply biaxial tension strength still falls short of the author's prediction, even when the transverse properties have been adjusted to match the uniaxial tensile strengths reasonably well. Surprisingly, the best agreement seems to be with the in-plane shear (equal and opposite tension and compression) state of stress.

It is difficult to make concrete comparisons with any theory using a progressive failure model because, as indicated in Figure 14, also taken from Tsai's Composite Design book, his failure envelope will collapse onto that for the maximum strain theory if one presupposes the necessary amount of matrix degradation. (There seems to be an error in coding his program because the strain in the compression-compression quadrant has collapsed onto the value of strain entered for transverse tension, not longitudinal compression.) However, the agreement achieved in the tension-tension quadrant by invoking matrix degradation has invalidated the agreement previously reached for the in-plane shear loads.

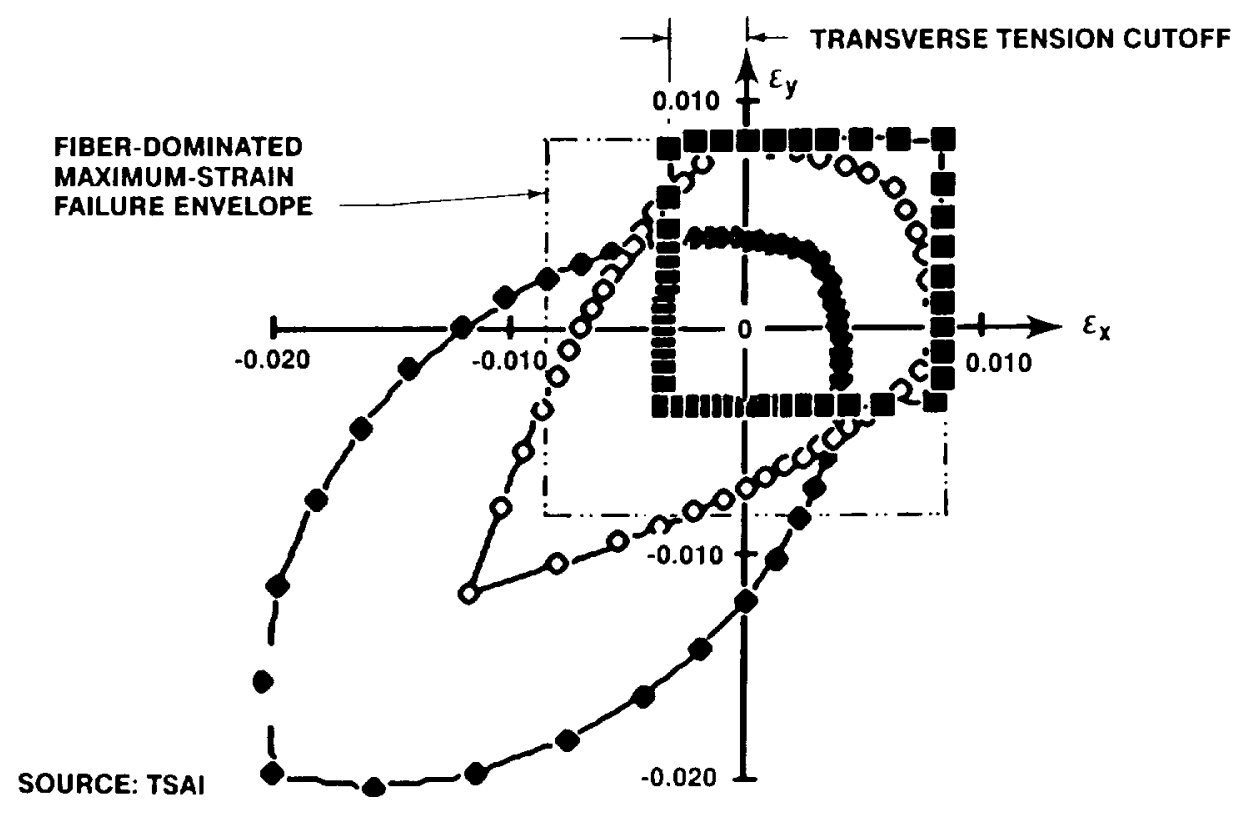

- $\mathrm{Em}^{\star}=1 \quad$. O- $E \mathrm{~m}^{*}=0.3 \quad-\mathrm{Em} \mathrm{m}^{*}=0.01$

LPF ENVELOPES FOR QUASI-ISOTROPIC T/300/N5208 CFRP LAMINATE WITH DEGRADATION FACTOR EQUAL TO 1, 0.3, AND 0.01

FIGURE 14. TSAI'S FIRST- AND LAST-PLY FAILURE ANALYSES SHOWING PROGRESSIVE TRANSFORMATION INTO MAXIMUM-STRAIN FAILURE ENVELOPE 
Given the difficulty of making comparisons with a moving target, as the degree of matrix degradation is altered, one is entitled to ask whether or not it would have been easier to go directly to the maximum-strain failure model instead of arriving at it indirectly via adjustments to the transverse properties entered into some other failure model which would not at first give acceptable answers. The abuse of progressive failure the ories to "enhance" predicted composite laminate strengths will be discussed in a future work.

A comparison of Figures 12 through 14 indicates that no matter what degree of matrix degradation is assumed, no single set of input properties for Tsai's theory will simultaneously match the author's predic ions for uniaxial and biaxial states of stress. Even when the transverse properties are suitably "adjusted" to match the uniaxial tensile and compressive strengths, the predicted biaxial tension strength will still be too small and the biaxial compressive strength too large.

In theory, one could always add two more adjustable parameters to the lamina failure model, to be set to match the biaxial testing of two cross-plied laminates. Ashizawa, in Reference 20, did so by using a cutoff based on measured fiber-dominated in-plane shear strengths of $\pm 45^{\circ}$ laminates. However, while this technique worked whenever the measured shear strength was accurate, the predictions were obviously inconsistent whenever the shear measurement was far too low. Unless one had a valid physical model to guide the process. it is likely that those particular biaxial tests would be inconsistent with predictions based on other biaxial tests. And, if one really did have a reliable physical model, one would not need any additional terms.

The quadratic "failure criteria" for fibrous composites are not the first unsound theories which are caf able of predicting some numerically correct answers to problems despite a consistent inability to solve other problems. The beliefs of the Flat Earth Society come readily to mind. While the old idea that the sun revolves around the earth is no longer taught, many celestial and seasonal observations were explained at the time by use of this model. The author can only hope that it will take less time to recognize the correct way to predict the strength of composite laminates than it took to reach agreement on a model for the solar system.

Another failing of these abstract mathematical failure "criteria" is exposed by a physical assessment of the most severe "triaxial" stresses that can be applied. * As the author noted in 1985 in Figure 13 of Reference 13, the cross section of the failure envelope looking along the biaxial stress line must be rectangular, as show'n in Figure 10. For the case of a quasi-isotropic laminate, the specific load of equal and opposite $\sigma_{x}$ and $\sigma_{y}$ strisses in the absence of any in-plane shear stress $\tau_{x y}$ induces no load in either the $+45^{\circ}$ or $-45^{\circ}$ fibers. Most of it is reacted by axial tension in the $0^{\circ}$ fibers, for example, and simultaneous compression in the $90^{\circ}$ fibers. A very small fraction of the load is reacted by shearing the resin matrix. On the other hand, the application of a sure in-plane shear load to the same laminate, with respect to the same reference axes, would load up the $\pm 45^{\circ}$ fibers while leaving the $0^{\circ}$ and $90^{\circ}$ fibers unloaded. This particular cross section of the failure envelope is thers fore rectangular because there is essentially no interaction between the loads, one of which is carried by the $0^{\circ} / 90^{\circ}$ fibers while the other is resisted by the $\pm 45^{\circ}$ fibers. The form of the abstract mathematical failure envelines in Figure 11 is in stark contrast to Figure 10, being smoothly curved all over.

The failure envelopes in Figure 11 are obviously also in error at the biaxial tension and biaxial compression points. Since all fibers are equally strained under those conditions, it is physically impossible to add in-plane shear loads without decreasing the in-plane direct loads. The ends of the failure envelope must be pointed not rounded as they are in Figure 11.

The reason for these errors is that Tsai's fictitious failure criterion, cited on p. 11-5 of Reference 19, contains a mixture of unrelated reference strengths, some pertaining to the fiber and others to the matrix. Tsai's forr pula and its many clones are restricted in validity to truly homogeneous materials exhibiting only one failure meshanism for all the states of combined stresses being considered. And, under such circumstances, the use of four

\footnotetext{
* Actually, it is the combination of biaxial in-plane direct loads with additional in-plane shear, so it is really a case of biaxial loads 'vith respect to different axes.
} 
or five test measurements to characterize the strength of the material should not be necessary. For distinctly heterogeneous materials such as fiber-polymer composites, on the other hand, it is necessary to write separate failure criteria against the fibers, the matrix, and possibly also the interface between the two. Further, additional criteria are needed whenever multiple failure modes are possible for any constituent.

There should perhaps be additional interlaminar criteria for the immediate proximity of any boundaries, but this refinement is customarily ignored, along with stacking-sequence effects, which is why every so often composite laminates with excessive clustering of parallel fiber layers delaminate during cooldown before they are even removed from the autoclave. And more often than not, a laminate was designed that way because some computer "optimization" program was used to identify the most "suitable" laminate instead of allowing accumulated experience to dictate that there be a minimum percentage of plies in each of the four standard directions and that there be strict limits on the clustering of parallel plies. Tsai's position on this matter is stated on p. 7-1 of Reference 19. "For symmetric laminates subjected to in-plane loads only, the stacking sequence of plies is not important." He accounts for stacking sequence only when studying the bending of laminates and all but ignores the issue of edge delaminations, while concentrating on intraply failures.

A major difference between the author's methods of predicting the strength of fibrous composites and those typified by the works of Tsai is that, in the author's case, minor changes in "lamina" properties do not affect the basic form of the failure envelopes. The failure envelope has remained characteristically flat-faceted since the very first report on the subject in 1984 (see Reference 21). Each facet has been defined by the failure of one particular fiber direction under a uniform failure mode throughout. The intersections of the facets denote the simultaneous failure of two or three fiber directions, depending on how many facets intersect. Reference 22 even includes parametric studies showing the small effects of systematic variations in material properties. Yet a study of Reference 19, for example, will show an endless variety of shapes, some associated with different fiber patterns but many caused merely by a change in the level of "degradation" due to matrix "cracking." Such variability does not inspire confidence in a theory.

The author's failure model for composite laminate analysis has been criticized as being too simplistic by some well-regarded researchers. A particular stumbling block is that the final failure envelope shows only one line for compressive failures while there is considerable evidence that several failure modes are possible. This is not germane to the level of analysis being performed here. Also, the critics seem to have missed the very clear coverage of both shear failures of the fibers and some not necessarily defined form of compressive instability, depending on the particular composite material under investigation. The author is interested in only the weakest of the possible failure mechanisms, whatever it may be. It might even change with operating environment and certainly changes between unidirectional and cross-plied laminate patterns. There is no need for the author to address this issue of multiple possibilities for any one facet of the failure envelope because the experimentally derived input data will automatically identify the weakest mechanism provided that the test coupon and fixture are representative of the real structure.

The reluctance to admit that the art of predicting the strengths of composite laminates has not been perfected is apparent in a response to the author's attempts to find interest in improving the analytical techniques. If one were to believe the predictions of the Tsai-Wu "failure theory," for example, one would be forced to conclude that the underwater compressive strength of a composite submarine hull could be increased substantially by reducing the interlaminar (and hence transverse-tension) strength of the lamina, as explained in Figure 15. While many got the message, one response was; "That sounds like a great idea. How do we reduce the interlaminar tension strength?"

\section{A MAJOR INCONSISTENCY IN STANDARD COMPOSITE FAILURE THEORIES}

Analytical predictions of strength based on a combination of orthogonal unidirectional tape layers have no resemblance whatever to the predicted strengths of the same fibers in the same resin, in the form of a cloth 


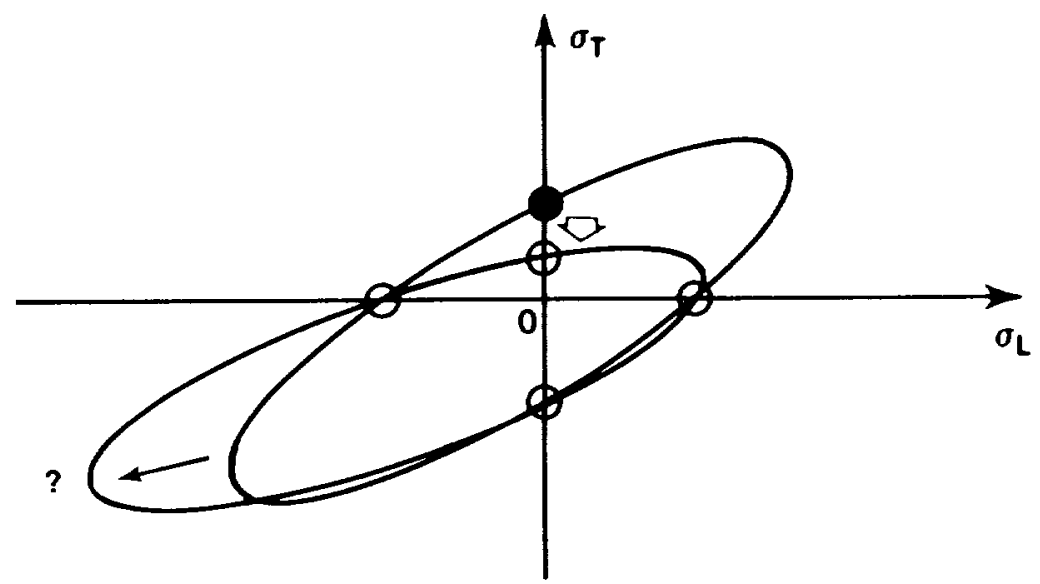

WOULD ANYONE BELIEVING THIS ANALYSIS BE WILLING TO PUT TO SEA FOR THE DIVING TRIALS?

\section{FIGURE 15. "IMPROVED" COMPOSITE MATERIAL FOR SUBMARINE HULLS BY DECREASING TRANSVERSE-TENSION STRENGTH OF UNIDIRECTIONAL LAMINA}

laminate, even when the two laminates have precisely the same elastic constants and the fibers have preci iely the same failure stress or strain. The issue has nothing to do with kinks in the woven fabric; the dissimilarity also exists when the bidirectional lamina is made from unkinked dry stitched preforms which are subsequently impregnated with resin.

Figure 16 illustrates this point very clearly. The irreconcilability is quantified in Figure 17 by various analyses of $0^{\circ}$ and $90^{\circ}$ and $0^{\circ} / 90^{\circ}$ laminates. The analyses are symmetric about the diagonal running from the lower left to the upper right, so only half of each is shown, with the "tape" analyses in the lower right and the equivalent "cloth" analyses in the upper left. Precisely the same fiber strains-to-failure are used throughout the analyses, and the output of the tape laminates analysis is used to define the elastic constant inputs for the cloth analysis. The first-ply failure (FPF) analyses on the right of the figure show a gross underestimate of the tensile strengt' $1 s$, ${ }^{*}$ with respect to both the author's theory and the well-known maximum-strain failure model, which is compensated for by a gross overestimate of the compressive strengths. The computer code then "modifies" the tape material properties and recalculates last-ply failures (LPF) which appear to agree much better with the auth or's theory. Tsai's reduction in transverse stiffness to achieve this transformation is directly equivalent to the author's recommendations in Reference 22 . There was concern that the predictions of the BLACKART computer code would be invalidated by premature transverse-tension failures of the type responsible for the distortion of the FPF envelope in Figure 17. But the author's approach has been described as merely a fudge. Perhaps it wculd have appeared more scientific if it had been accomplished by a computer code.

The FPF predictions shown in the upper left of Figure 17 should correspond to fiber-dominated failures $c$ nd, indeed, they agree well with the author's predictions, apart from the minor problem of physically impossible small overestimates of strength whenever the two in-plane stress components have the same rather than opposite

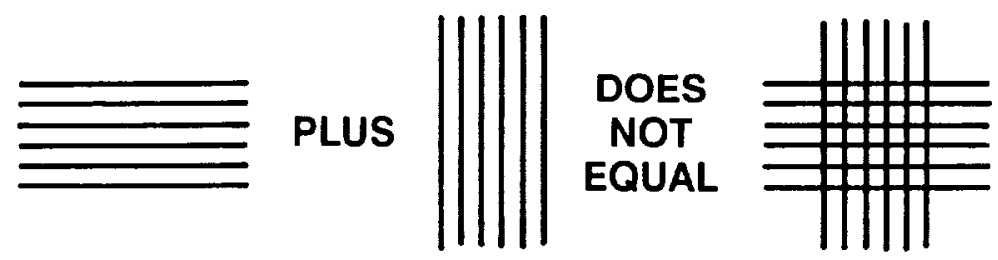

FIGURE 16. FATAL FLAW IN TENSOR-POLYNOMIAL COMPOSITE FAILURE CRITERIA

\footnotetext{
- The cusp at the biaxial tension point in Figure 9 results from Swanson's interpretation that if all the laminae are equally critical according to the FPF analysis, no enhancement of strength is possible under an LPF analysis. Only the transverse ply propertics were degraded in Figure 17.
} 


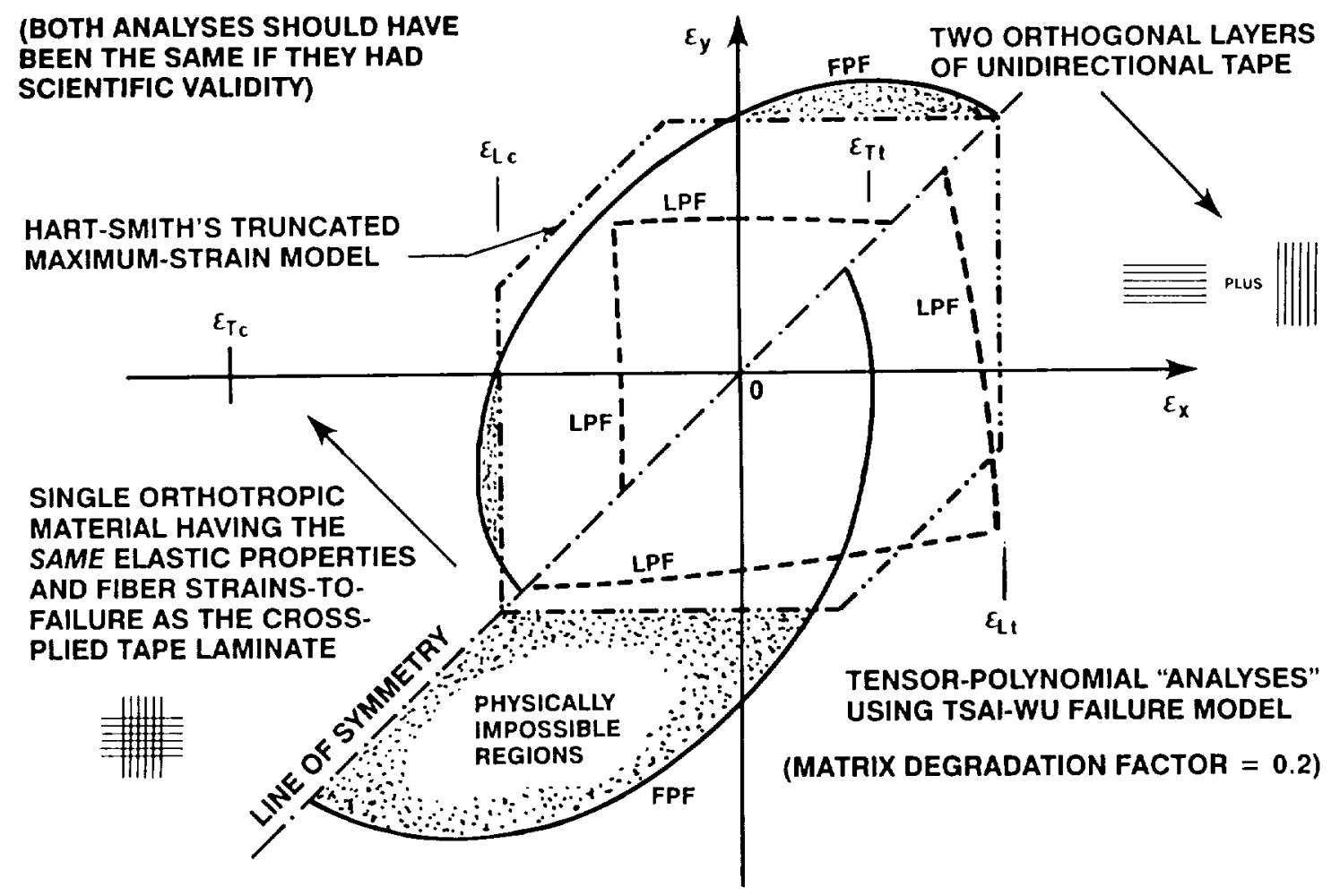

FIGURE 17. CONFLICTING ANALYSES OF THE SAME $0^{\circ} / 90^{\circ}$ COMPOSITE LAMINATE

signs. However, this apparent reconciliation is undermined by further computer coding in the form of LPF predictions for the cloth laminate which are significantly weaker. No justification for this second analysis has been found in Tsai's book, and no physical explanation is given in the text accompanying the computer code.

However, the good agreement between the "cloth" FPF analysis in Figure 17 and the author's analysis reinforces the author's repeated claims over the years that the mechanical properties needed for predicting the strength of cross-plied composite laminates are those prevailing in the cross-plied laminate, not those for the unidirectional tape laminate in isolation. If, instead of proceeding from the tape to a cloth analysis, the process had been reversed to establish representative in-situ mechanical properties for the unidirectional tape in the presence of orthogonal fibers, the "tape" analysis for the combination of unidirectional $0^{\circ}$ and $90^{\circ}$ plies would also have been correct because all the predicted failures would have been fiber-dominated. The only thing found wrong would be the original hypothesis that it was appropriate to create a composite failure model based on measured tensile and compressive strengths in the longitudinal and transverse directions for a unidirectional tape laminate.

\section{CONCLUSIONS}

One would have to conclude from the simplicity of the author's Ten-Percent Rule for approximate analysis of fibrous composite laminates that it should be extremely difficult to develop computerized composite "failure theories" that are incapable of correctly predicting the uniaxial strengths under tension and compression. Surprisingly, the literature on the subject shows that many authors have failed to predict even these simplest of laminate strengths.

Of the well-established failure models, only the empirical maximum-strain model has been found by the author and others to lead to acceptable predictions for even the simplest load cases. This same theory has 
already been confirmed by experiment to be valid throughout the tension-tension quadrant. And the author expects that it will eventually be proven equally valid throughout the compression-compression quadrant when reliable test data are generated. However, this theory has been shown to be unacceptably unconservative, ty $) \mathrm{i}-$ cally by 60 percent, for the in-plane-shear loads in which the biaxial stresses are of opposite sign.

If it were not for this in-plane-shear case, there would be no criterion by which to distinguish between the maximum-strain theory and the author's generalization of the Tresca (maximum-shear-stress) failure model. This particular biaxial stress state is crucial in selecting one of the two theories. The criticality applies equally in assessing other physically plausible failure models, some of which have considerable experimental support for other states of stress. For instance, as shown in Figure 5, a failure model based on a combination of notch sensitivity in the tension-tension quadrant and some form of compressive instability throughout the compression-compression domain cannot be challenged except for the need to find a third mechanism to eliminate un: cceptably unconservative predictions throughout the tension-compression (shear) states of biaxial stress. Neitt er the author nor anyone else is in a position to challenge such theories if they are not assessed for all states of uniaxial and biaxial stresses.

In applying and presenting the generalized maximum-shear-stress failure model, the author has already acknowledged the need to provide for at least one different failure mechanism, that of compressive instabil ty for the newer high-strain carbon fibers of very small diameters. Expressing his new failure theory with respect to the strain plane, even though it is really a stress-based criterion, makes it easy to superimpose additior al realistic failure modes. The author also acknowledges the need to provide for but only rarely use transverse matrix cracking for such composite materials as S-glass fibers in a brittle polymer matrix.

The author's failure model is set apart from the numerous abstract mathematical theories of anisotropic eli sticity by additional failure modes that can be superimposed on the basic shear failure envelope for the fibers without altering the predicted strengths for other failure modes. With the fictitious smooth curves drawn throu sh four unrelated measured strengths, on the other hand, a change in any one of these four calibration points alte rs every predicted strength except for the other three reference strengths. A weakness in transverse tensi: $n$ strength, for example, would be expected to cause predicted increases in the biaxial compression strength, wh le premature compressive failure by instability would be associated with a prediction that the biaxial tension strength had been enhanced.

It should now be evident that the innumerable abstract mathematical "failure theories" for fibrous compusites, which have been acknowledged as unreliable by their own originators the moment they had to invoke "progressive failure" models to achieve agreement with even the uniaxial tests, are beyond redemption as useful structural design tools when one also considers the biaxial stress states.

\section{ACKNOWLEDGMENT}

The author is indebted to J. B. Black, Jr., a kindred spirit whose high regard for publications on this subject is indicated by his Douglas Aircraft Company report entitled "Failure Criterion No. 1,075,372." His understanding of composite failure mechanisms permitted the rational analysis of the composite components on $t$ re C-17 aircraft, using an empirically established truncated maximum-strain model of the type shown in Figure 6, before the author had reexpressed his own generalized maximum-shear-stress failure criterion in the strain rather than stress plane.

\section{REFERENCES}

1. L. J. Hart-Smith, "Some Observations on the Analysis of In-Plane Matrix Failures in Fibrous Composite Laminates," Douglas Paper 8558, presented to 4th ASTM Symposium on "composite Materials: Fatigıte and Fracture," Indianapolis, Indiana, May 6-7, 1991. 
2. R. Hill, The Mathematical Theory of Plasticity, Oxford University Press, London, 1971, pp. 317-340.

3. S. W. Tsai, "Strength Characteristics of Composite Materials," NASA CR-224, April 1965.

4. R. E. Rowlands, "Strength (Failure) Theories and their Experimental Correlation," in Handbook of Composites, Vol. 3, Failure Mechanics of Composites, edited by G. C. Sih and A. M. Skudra, North-Holland, Amsterdam, 1985, pp. 71-125.

5. S. W. Tsai and E. M. Wu, "A General Theory of Strength for Anisotropic Materials," Journal of Composite Materials, Vol. 5, January 1971, pp. 58-80.

6. L. J. Hart-Smith, "Simple Methods for Predicting the Strength of Cross-Plied Fibrous Composite Laminates," Douglas Paper 8377, presented to SAMPE Composites Seminar on "Repair, Maintainability and Supportability," San Diego, California, October 19, 1989.

7. A. Puck, "Festigkeitsberechnung an Glasfaser/Kunstoff-Laminaten bei zusammengesetzter Beanspruchung," (Stress Analysis of Glass Fiber in Composite Laminates), Kuntstoffe, Bd 59, 1969, pp. 780-787.

8. Anon, "Failure criteria for an individual layer of a fibre reinforced composite laminate under in-plane loading," Engineering Sciences Data Unit, Item 83014, June 1986.

9. L. J. Hart-Smith, “A New Approach to Fibrous Composite Laminate Strength Prediction,” Douglas Paper 8366, Proceedings of the 8th DoD/NASA/FAA Conference on Fibrous Composites in Structural Design, Norfolk, Virginia, November 28-30, 1989, NASA CP-3087, Part 2, pp. 663-693.

10. G. C. Grimes, K. W. Ranger, and M. D. Brunner, "Element and Subcomponent Tests," in Engineered Materials Handbook, Vol. 1, Composites, edited by C. A. Dostal, ASM International, Metals Park, Ohio, 1987, pp. 313-345.

11. R. N. Hadcock, J. Saurez, and J. B. Whiteside, "Advanced Composite Wing Structures Boron-Epoxy Design Data, Vol. 1, Design Data Summary," Grumman Aerospace Corporation, Technical Report AC-SM-ST8085, March 1970.

12. J. B. Black, Jr., "Failure Criterion No. 1,075,372," internal Douglas document dated 4-22-88.

13. L. J. Hart-Smith, "Simplified Estimation of Stiffnesses and Biaxial Strengths for Design of Carbon-Epoxy Composite Structures," Proceedings of 7th DoD/NASA Conference on Fibrous Composites in Structural Design, Denver, Colorado, June 17-20, 1985, AFWAL-TR-3094, pp. V(a)-17 to V(a)-52.

14. L. J. Hart-Smith, "A Biaxial-Strength Test for Composite Laminates Using Circular Honeycomb Panels," Douglas Paper 7974, Proceedings of 33rd International SAMPE Symposium and Exhibition, Anaheim, California, March 7-10, 1988, pp. 1485-1498.

15. S. R. Swanson and M. Nelson, "Failure Properties of Carbon/Epoxy Laminates Under Tension-Compression Biaxial Stress," in Composites '86: Recent Advances in Japan and the United States, edited by K. Kawata, S. Umekawa, and A. Koyabashi, Proceedings of the Third Japan-U.S. Conference on Composite Materials, Tokyo, Japan, June 23-25, 1986, pp. 279-286.

16. L. J. Hart-Smith, "A Radical Proposal for In-Plane Shear Testing of Fibrous Composite Laminates," Proceedings of 32nd International SAMPE Symposium and Exhibition, Anaheim, California, April 6-9, 1987, pp. 349-359; reprinted in SAMPE Quarterly, Vol. 19. No. 1, October 1987, pp. 7-13.

17. L. J. Hart-Smith, "Fibrous Composite Laminate Strength Predictions Demystified," Proceedings of 11th European SAMPE meeting, H. L. Hornfeld ed., Basel, Switzerland, May 29-31, 1990, pp. 365-380.

18. M. E. Waddoups, "Characterization and Design of Composite Materials," in Composite Materials Workshop, edited by S. W. Tsai, J. C. Halpin, and N. J. Pagano, Technomic, Connecticut, 1968, pp. 254-308.

19. S. W. Tsai, Composites Design, 4th edition, Think Composites, Dayton, Ohio, 1988.

20. M. Ashizawa, "Semi-Empirical Approach to Failure Criteria for Laminated Composites," Proceedings of 7th DoD/NASA Conference on Fibrous Composites in Structural Design. Denver, Colorado, June 17-20. 1985, pp. V(a)-53 to $V(a)-73$.

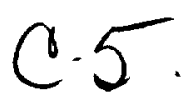


21. L. J. Hart-Smith, "Approximate Analysis Methods for Fibrous Composite Laminates Under Combined Biaxial and Shear Loading," Douglas Aircraft IRAD Technical Report MDC-J9898, March 1984.

22. D. A. Peterson and L. J. Hart-Smith, "A Rational Development of Lamina-to-Laminate Analysis Methods for Fibrous Composites," Proceedings of 9th ASTM Symposium on Composite Materials: Testing and Design, S. P. Garbo ed., Sparks, Nevada, April 27-29, 1988, ASTM STP 1059, February 1990, pp. 86-120. 